\title{
ABSTRACT
}

Title of Dissertation:

Dissertation Directed By:

\section{DOES NEGATIVE SELF-IMAGERY PLAY A CAUSAL ROLE IN SOCIAL PHOBIA AMONG ADOLESCENTS?}

Candice A. Alfano, Ph.D., 2005

Professor Deborah C. Beidel

Department of Psychology

The current study was designed to examine whether negative self-imagery is a significant factor in the development of social phobia among adolescents. Although some adult models of social phobia posit that negative self-imagery serves to increase anxiety and decrease performance within social contexts, few studies have directly examined this relationship and no study has examined self-imagery among socially phobic adolescents. For the current study, negative self-imagery was manipulated among a group of non-anxious adolescents (IMAG) during two social tasks. Levels of anxiety, specific thoughts, expected and self-rated performance, and observer-rated performance and social skill were compared to both socially-phobic and control adolescents. Results revealed few differences in terms of observer-rated performance and specific social skill between the IMAG and control groups of adolescents, although the socially-phobic group was consistently rated to exhibit poorer performances and decreased social skill. The IMAG group reported marginally significant increases in their anxiety levels during both social tasks. Interestingly, these adolescents reported similar (increased) rates of anxiety during an additional social interaction task where they were instructed to use positive self-imagery. The IMAG group also reported decreases in performance compared to the control group. This finding appears to be explained primarily based on the adolescents' belief that they were unable to hide their anxiety rather than a decrease in social skill (such as reported by socially-phobic youth). Further, the IMAG group reported an overall fewer number of cognitions than both groups during the social interaction task, potentially indicating a significant decrease in cognitive resources based on the use of self-imagery. Overall findings from this investigation do not support the hypothesis that negative self-imagery plays a causal role in the development of social phobia among adolescents. Rather, results indicate that an excessive self-focus within social contexts, together with normal developmental increases in self-consciousness during the adolescent years, may pose a specific risk for development of the syndrome. These findings provide a developmental understanding of the factors involved in the onset of social phobia, as well as those symptoms that may be germane to the maintenance of the disorder over time. 


\title{
DOES NEGATIVE SELF-IMAGERY PLAY A CAUSAL ROLE IN
} SOCIAL PHOBIA AMONG ADOLESCENTS?

\author{
By \\ Candice A. Alfano \\ Dissertation submitted to the Faculty of the Graduate School of the \\ University of Maryland, College Park, in partial fulfillment \\ of the requirements for the degree of \\ Doctor of Philosophy \\ 2005
}

Advisory Committee:

Professor Deborah C. Beidel, Chair

Professor Samuel M. Turner

Professor Barry Smith

Assistant Professor Andrea Chronis

Professor Hedwig Teglasi 
(C) Copyright by

Candice A. Alfano 2005 


\section{Dedication}

This dissertation is dedicated to my mother, Diane Alfano, who has never remitted in her support of my choices in this life. Not even for a day. 


\section{Acknowledgements}

I wish to thank all the members of my dissertation committee for their suggestions and guidance in the completion of this project. To my fellow graduate students and friends, especially Lisa Sanchez and Armando Pina, thank you for providing the communal support and encouragement needed in order to complete the entire graduate process. To Dr. Wendy Silverman, thank you for setting the stage for an exciting career in clinical child research. I also wish to extend my sincere gratitude to my advisor and mentor, Dr. Deborah Beidel, who has provided me with countless opportunities for professional growth over the past few years. Her direction and encouragement have occupied a central role in my scholastic development and I genuinely thank her for all of her efforts. Finally, to the late Dr. Samuel M. Turner, who passed a mere nine days after attending my final defense, it has been both an honor and a privilege to have been your student. Your dedication and commitment to the science of clinical psychology have served as an ideal for my future career and the field as a whole. Your guidance and influence shall not be forgotten. 


\section{Table of Contents}

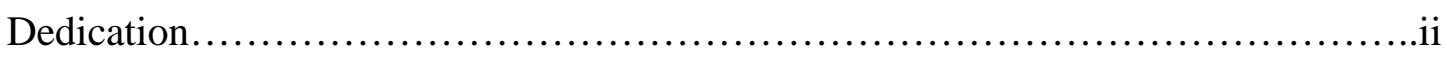

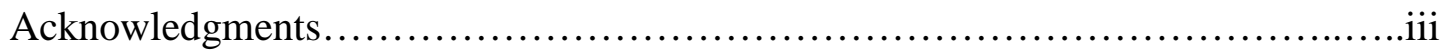

List of Tables..............................................................

List of Figures............................................................

Chapter 1: Clinical Syndrome of Social Phobia..................................... 1

1.1 Diagnostic Criteria.............................................

$1.2 \quad$ Age of Onset................................................

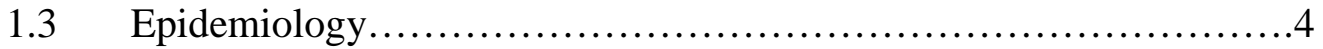

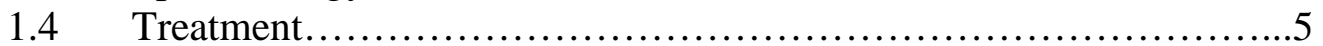

Chapter 2: A Cognitive Model of Social Phobia.................................. 9

Chapter 3: Clinical Features of Childhood Social Phobia.......................... 14

$3.1 \quad$ Negative Self-Imagery....................................... 14

3.2 Negative Cognition...............................................18

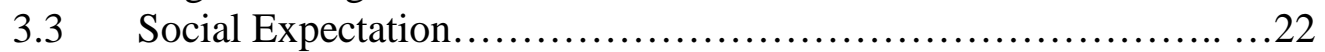

3.4 Social Skills.................................................. 27

Chapter 4: Implications for the Current Study................................. 31

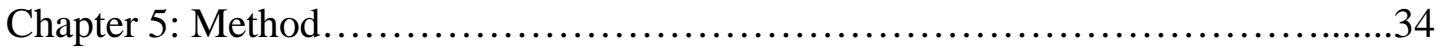

$5.1 \quad$ Subjects..................................................... 34

5.1 .1 Patient Sample.......................................34

5.1.2 Self-Imagery and Control Adolescents.........................35

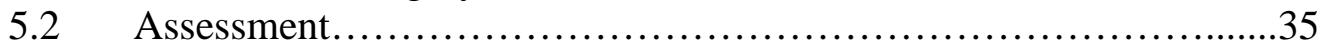

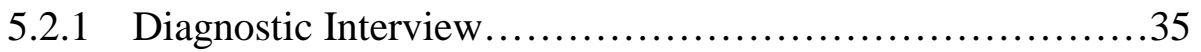

5.2.2 Self-Report..............................................

5.2.3 Behavioral Assessment.....................................38

5.3 Video-Mediated Recall of Cognition............................. 39

$5.4 \quad$ Procedures.................................................. 40

5.4.1 Manipulation of Self-Imagery ..........................42

Chapter 6: Results...................................................... 44

6.1 Preliminary Analyses.........................................44

6.1.1 Demographics.......................................44

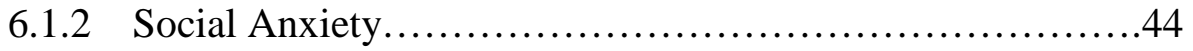

6.1.3 Self-Imagery Integrity Check...........................45

6.2 Performance Anxiety............................................45

6.3 Self-rated Performance.......................................46

6.3.1 Expected Performance................................46

6.3.2 Performance Ratings...................................47

6.3.3 Expected versus Actual Performance.......................49

6.4 Observer ratings.............................................49

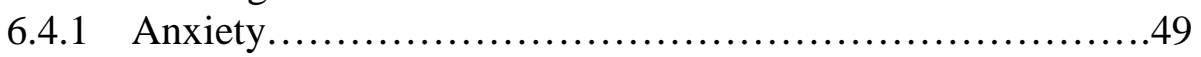

6.4.2 Performance............................................50

6.4 .3 Social Skill...........................................50

$6.5 \quad$ Cognition................................................... 51 
6.5.1 Data Reduction......................................51

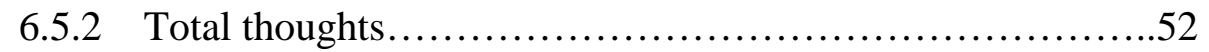

6.5.3 Role-Play Task.......................................52

6.5.4 Read-Aloud Task........................................53

6.6 Secondary Analyses.............................................54

6.6.1 Changes in Anxiety.......................................54

6.6.2 Correlational Analyses..................................55

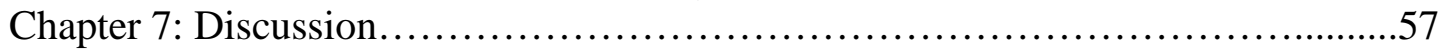

Appendices...........................................................68

A. Recruitment Flyer............................................68

B. Consent/Assent forms.............................................69

C. Dialogues for Behavioral Assessment................................73

D. Self-report Measures..............................................77

E. Observer-report Measures.......................................... 82

F. Video-mediated Recall Sheets....................................8 87

Bibliography........................................................... 89 


\section{List of Tables}

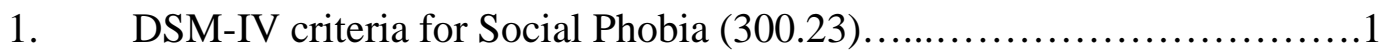

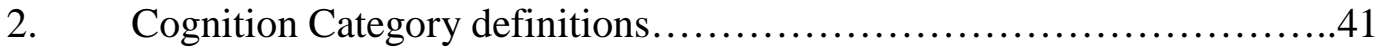

3. Demographic Characteristics....................................44

4. Self-reported Anxiety......................................46

5. Mean Expectation and Self-Performance ratings......................48

6. Mean scores and standard deviations for Role-play Cognitions...........53

7. Mean scores and standard deviations for Read-aloud Cognitions...........54

8. Correlations for the Role-play task among IMAG adolescents ...........55

9. Correlations for the Read-aloud task among IMAG adolescents .........56 


\section{List of Figures}

1. Expected versus Actual Performance on the Read-aloud...................49

2. Mean number of reported Cognitions by Group........................52

3. Change in Anxiety for Self-imagery Role-plays.......................55 


\section{Chapter 1: Clinical Syndrome of Social Phobia}

\subsection{Diagnostic Criteria}

According to DSM-IV diagnostic criteria, social phobia refers to "a marked and persistent fear of one or more social or performance situations in which the person is exposed to unfamiliar people or to possible scrutiny by others" (DSM-IV; APA, 1994, p. 416). While social phobia (also called social anxiety disorder) has long been recognized among adults, the syndrome is also common among children and adolescents. The specific diagnostic criteria from the DSM-IV are listed below.

Table1. DSM-IV criteria for Social Phobia (300.23)

A. A marked and persistent fear of one or more social and performance situations in which the person is exposed to unfamiliar people or to possible scrutiny by others. The individual fears that he or she will act in a way (or show anxiety symptoms) that will be humiliating or embarrassing. Note: In children, there must be evidence of the capacity for ageappropriate social relationships with familiar people and the anxiety must occur in peer settings, not just in interactions with adults.

B. Exposure to the feared social situation almost invariably provokes anxiety, which may take the form of a situationally bound or predisposed Panic Attack. Note: In children, the anxiety may be expressed by crying, tantrums, freezing, or shrinking from social situations with unfamiliar people.

C. The person recognizes that the fear is excessive or unreasonable. Note: In children, this feature may be absent

D. The feared social or performance situations are avoided or else are endured with intense anxiety or distress.

E. The avoidance, anxious anticipation, or distress in the feared social or performance situation(s) interferes significantly with the person's normal routine, occupational (academic) functioning, or social activities or relationships, or there is marked distress about having the phobia.

F. In individuals under age 18 years, the duration is at least 6 months

G. The fear or avoidance is not due to the direct physiological effects of a substance (e.g., a drug of abuse, a medication) or a general medical condition and is not better accounted for by another mental disorder (e.g., Panic Disorder With or Without Agoraphobia, Separation Anxiety Disorder, Body Dysmorphic Disorder, a Pervasive Developmental Disorder, or Schizoid Personality Disorder).

H. If a general medical condition or another mental disorder is present, the fear in Criterion A is unrelated to it (e.g., the fear is not of Stuttering, trembling in Parkinson's disease, or exhibiting abnormal eating behavior in Anorexia Nervosa or Bulimia Nervosa). 
As indicated by DSM-IV criteria, a diagnosis of social phobia is appropriate when patterns of avoidance and distress interfere with a child's normal routines, academic functioning or social relationships, or when there is marked distress about having the phobia. The feared social or performance situations invariably provoke significant anxiety, and a particular fear of acting in such a way that is humiliating or embarrassing in front of others is common. Generally, any situation where a child may be observed or scrutinized by others may be feared. Thus, similar to adults, children with social phobia fear speaking, reading, eating, writing in public, going to parties, using public restrooms, speaking to authority figures, and informal social interactions (Beidel \& Turner, 1998).

Many of the diagnostic criteria for social anxiety disorder are identical for adults and children. However, the most recent version of the DSM includes specific descriptors related to the clinical presentation of social phobia in children. For example, the DSM-IV criteria specify that for children "there must be evidence of the capacity for age appropriate social relationships with familiar people" and "the anxiety must occur in peer settings, not just in interactions with adults" (p. 417). These clinical descriptors are helpful in that they distinguish children with social phobia from children who may have social difficulties related to other psychosocial problems or developmental disorders. Also, the behavioral expression of anxiety in children with social phobia sometimes differs from adults. According to the DSM-IV, "in children, anxiety may be expressed by crying, tantrums, freezing, or shrinking from social situations with unfamiliar people"(p. 417). However, the most common physical symptoms appear to include choking, flushes or chills, palpitations, fainting, 
shaking, feeling like dying and headaches (Beidel, Christ, \& Long, 1991). Other symptoms may include stomachaches and occasional panic attacks. Lastly, unlike adults, the current diagnostic criteria acknowledge that children may not recognize that their social fears are excessive or unreasonable.

\subsection{Age of Onset}

The modal age of onset of social phobia is during early to middle adolescence (Mannuzza, Fyer, Liebowitz \& Klein, 1990; Ost, 1987; Schneier, Johnson, Hornig, Liebowitz \& Weissman, 1992; Turner, Beidel, Dancu \& Keys, 1986) although the disorder has been clinically identified as early as age 7 (Beidel \& Turner, 1988; Beidel, Turner \& Morris, 1999). Further, many adults with social phobia commonly report that their social fears have been constant since their onset and describe themselves as having social phobia "all of their lives" (Schneier et al., 1992; Solyom, Ledwidge \& Solyom, 1986). Overall, social phobia tends to have an early onset and a chronic course. In a recent retrospective study, only half of those with a history of social phobia had recovered from the disorder (DeWit, Ogborne, Offord \& MacDonald, 1999). The strongest predictor of recovery appears to be a later age of onset of social fears. Those who reported an onset of social phobia after the age of 13 were more than 8 times more likely to recover from their illness than those who reported an age of onset before the age of 7 . These findings are consistent with other findings reported by Davidson (1993) based on data from the Epidemiological Catchment Area Survey indicating that onset of social phobia prior to the age of 11 is 
predictive non-recovery in adulthood and suggests that intervention should be initiated as early as possible.

\subsection{Epidemiology}

Recent estimates of the prevalence of childhood social phobia indicate that up to $3 \%$ to $4 \%$ of children may be affected (Beidel, Turner \& Morris, 1999), placing it among the most commonly diagnosed problems among school-aged children. In fact, some of the most recent prevalence rates indicate that up to $10-15 \%$ of adolescents may receive a diagnosis of social phobia (Heimberg et al., 2000; Wittchen et al., 1999). In one retrospective survey by DeWit and colleagues (1999), the lifetime prevalence rate of social phobia was reported to be $13.7 \%$ (with a median age onset of 12.7 years). These recent estimates are considerably higher than earlier estimates that came from the National Institute of Mental Health Epidemiological Catchment Area study (ECA), one of the largest epidemiological samples for the study of psychopathology in the United States. Studies based on ECA samples reported lifetime prevalence rates of social phobia to be approximately $2 \%$ (Robins et al., 1984; Schneier et al., 1992). Although such differences in the estimated prevalence of social phobia may be the result of both the specific assessment methodologies and samples used, it also has been proposed that current epidemiological rates for social phobia among child populations may be somewhat inflated as a result of changes in DSM criteria. Specifically, with the publication of DSM-IV, Overanxious Disorder (OAD) and Avoidant Disorder (AVD) were eliminated as childhood diagnoses. As defined in DSM-III-R, both OAD and AVD encompassed some degree of social self- 
consciousness, social avoidance, and excessive worry related to one's performance and appropriateness of behavior. Based on the partial overlap among criteria for OAD, AVD and social phobia, children formerly meeting criteria for DSM-III-R OAD or AVD would likely receive a diagnosis of social phobia under DSM-IV. Although there has been some research to support this revised classification (Tracey, Chorpita, Douban \& Barlow, 1997; Kendall \& Warman, 1996), others have suggested a potential over-diagnosis of social phobia due in part to changes in DSM-IV (Beidel, Turner \& Morris, 1999). Nonetheless, of all the anxiety disorders, social phobia remains the most prevalent.

Children with social phobia also commonly meet criteria for at least one additional Axis I diagnosis. For example, Beidel, Turner and Morris (1999) examined comorbidity rates of social phobia in preadolescent children and found $60 \%$ of children with social phobia to have a second Axis I diagnosis, of which $36 \%$ were additional anxiety disorders. Generalized anxiety disorder (10\%), attention deficit/hyperactivity disorder (10\%), and specific phobia (10\%) were the most common comorbid diagnoses. In addition, $8 \%$ of the children with social anxiety disorder were diagnosed with selective mutism, $6 \%$ with obsessive-compulsive disorder, $2 \%$ with panic disorder, $2 \%$ with adjustment disorder with depressed mood, and $2 \%$ with depression.

\subsection{Treatment}

Although several treatment modalities such as cognitive-behavioral therapy, social skills training, and pharmacological treatments have been found to be 
efficacious in the treatment of childhood social phobia, in general, the literature on efficacious treatments for children trails in comparison to that for adults. One apparent problem is that a majority of research in this area is conducted with heterogeneous groups of anxiety-disordered children as opposed to samples comprised exclusively of children with social phobia. More recently however, a few controlled studies within the childhood anxiety literature have reported the efficacy of cognitive behavioral therapy and social skills training specifically with socially phobic children and adolescents (Albano, 2000; Beidel, Turner, \& Morris, 2000; Spence, Donovan \& Brechman-Toussaint, 2000). In addition to an exposure-based treatment component and social skills training, many interventions for childhood social anxiety also have included a specific treatment component aimed at reducing negative cognition. In general, the term negative cognition has been used to refer to cognitive phenomena including negative self-related thoughts, biased social interpretations, and decreased expectations of performance. However, although some studies have provided evidence of such cognitive distortions, other studies failed to find differences in cognition between anxious youth and normal controls (see Alfano, Beidel \& Turner, 2002 for a review). Further, there is some evidence from controlled treatment outcome studies to suggest that the specific inclusion of a cognitive component may not be necessary (e.g., Beidel, Turner \& Morris, 2000; Silverman et. al., 1999; Spence, Donovan \& Brechman-Toussaint, 2000). For example, Beidel, Turner and Morris (2000) recently evaluated the effectiveness of a multi-component behavioral treatment for childhood social phobia among a sample of 67 children ages 8 to 12 years. The treatment 
condition (Social Effectiveness Therapy for Children; SET-C) included group social skills training, peer-generalization experiences, and individual in-vivo exposure while the non-specific treatment condition was a test-taking and study skills intervention. At post-treatment, two thirds of the socially-phobic children in the SET-C group no longer received a social phobia diagnosis, versus $5 \%$ of children in the study skills groups. Additionally, although a specific cognitive assessment was not included among the treatment outcome measures, the cognitive items on the Social Phobia and Anxiety Inventory for Children (SPAI-C; Beidel, Turner, \& Morris, 1995) indicated significant improvement in cognitive symptoms for both treatment groups (Alfano, Beidel \& Turner, 2001). Similar results recently were reported by Pina, Alfano, Viana, Weems, and Silverman (2004) in a study using a heterogeneous sample of anxiety-disordered youth. In particular, anxious children who received either cognitive therapy or education support (which did not include a cognitive treatment component) showed similar decreases in cognitive errors following treatment.

In terms of pharmacological treatments, comparatively limited evidence exists for the efficacy of pharmacological agents in the treatment of childhood social phobia. Findings from available controlled trials using samples of anxious children/adolescents indicate that drug classes such as benzodiazepines and selective serotonin reuptake inhibitors (SSRIs) may be efficacious (Velosa \& Riddle, 2000; Wilens, Spencer, Frazier \& Biederman, 1998). However, most studies have not examined pharmacotherapy among samples of children with childhood social phobia only. Rather, a subgroup of socially-phobic children is commonly included in a larger sample of children with various anxiety disorders. Overall, although there is some 
evidence to indicate short-term improvement in anxious symptoms, the long-term efficacy of these medications in the treatment of social phobia among children/adolescents is unknown. 


\section{Chapter 2: A Cognitive Model of Social Phobia}

Currently, it is generally theorized that the core features of the childhood syndrome closely mirror those seen among adult social phobics. Specifically, most models of social anxiety characterize the disorder to include any number of physiological reactions to fear, various avoidant behaviors, as well as cognitive factors (e.g., negative self-images/ thoughts/ interpretations). In fact, according to some theorists, the later represent a central feature in both generating and maintaining social phobia over time. Although several (somewhat) distinct cognitive models of social phobia have been proposed, one current predominant model is based on the notion that socially-anxious individuals possess biases in the way they process, attend to, and expect to perform within social situations (Clark \& Wells, 1995). Clark and Wells' (1995) model poses that within social contexts, attention is shifted away from external social cues and instead, is excessively self-focused. According to the model, it is during this time that the social phobic is flooded with negative selfimages of his/her behavior. Based on the presence of such images, it is proposed that social phobics possess the (inaccurate) belief that others see him/her in the same negative fashion, resulting in continued feelings of excessive anxiety and decreased social performance.

To date, the presence of reoccurring negative self-images among social phobics has been reported by several investigators (Hackmann, Clark \& McManus, 2000; Hackmann, Surawy \& Clark, 1998; Hirsch, Clark \& Williams, 2004). For example, in one of the first studies of self-imagery in social phobia, Hackmann, 
Surawy and Clark (1998) investigated spontaneously occurring images among adult social phobics and non-patient controls using a structured interview. Overall frequency comparisons of negative self-imagery prior to or during anxiety-producing social situations revealed that social phobics experienced greater amounts of spontaneously occurring images than did control subjects. However, although investigations such as that by Hackmann and colleagues provide preliminary support for negative self-imagery in social phobia, one major limitation of this research is the reliance on retrospective report in establishing the presence of self-imagery. Recognizing this limitation, a more recent investigation by Hirsch and colleagues (2004) utilized a manipulation technique to more effectively assess the potential impact of negative self-imagery on anxiety and social performance among a group of adult social phobics. Results supported the role of negative self-imagery in increasing anxiety and decreasing performance among a sample of socially-phobic adults.

Although preliminary evidence for the role of negative self-imagery in social phobia exists, other conceptualizations of the disorder have focused on biological influences, previous negative experiences, and socially-avoidant behaviors as generating and maintaining the syndrome over time (see Hudson \& Rapee, 2000). For example, it has been estimated that negative (i.e., conditioning) social experiences are associated with the onset of social phobia in approximately 50-60\% of this population (Ost, 1987; Ost \& Hugdahl, 1981; Stemberger, Turner, Beidel \& Calhoun, 1995). Although such experiences are commonly linked to more specific forms of the disorder (as opposed to the generalized subtype), exceptions to this finding are not uncommon. For example, Stemberger, Turner, Beidel and Calhoun (1995) found that 
$56 \%$ of those with specific social phobia and $40 \%$ of those with generalized social phobia could recall a traumatic event that marked an increase in their phobic symptoms. Additionally, several studies of self-imagery among social phobics have reported that many of the images reported by socially-phobic individuals appear to be mere elaborations of previously traumatic social events (Hackmann, Clark \& McManus, 2000; Hackmann, Surawy \& Clark, 1998). In fact, one study reported a high correlation between the occurrence of these negative social experiences and the onset of the disorder (Hackmann, Clark \& McManus, 2000). As such, it is currently unclear whether the presence of negative self-imagery among social phobics may simply represent an eventual consequence, rather than the origin of the disorder. Another important aspect of Clark and Wells' (1995) model includes the use of "safety behaviors". The term "safety behaviors" refers to different cognitive and behavioral strategies used by social phobics in order to prevent or reduce negative social outcomes (Clark \& Wells, 1995). For example, socially-phobic individuals may be focused on remembering everything they have said previously in order to avoid appearing dull or stupid. Behaviorally, individuals may refrain from speaking or may speak very quickly in an attempt to avoid saying something wrong or incorrectly. They also may grip a glass tightly as to minimize hand trembling, or they may avoid eye contact in order to evade conversation. Although such behaviors may be perceived as skill deficits by others, Clark and Wells propose these behaviors to represent conscious attempts toward preventing negative social outcomes. Thus, because attention and behavior may be overly geared toward appearing favorable, the individual may actually be perceived as distracted, uninterested in the interaction 
itself, or lacking in social skills. Although findings from a few empirical studies have provided preliminary evidence for the use of safety behaviors among socially-phobic adults (e.g., Stopa \& Clark, 1993), currently, data based on the use of controlled experimental strategies is generally lacking. The use of safety behaviors has not been examined among socially-phobic youth.

With regard to socially-phobic child samples, several investigators have reported decreased social performances in relation to specific social skill deficits (Beidel, Turner \& Morris, 1999; Spence, Donovan \& Brechman-Toussaint, 1999). Models of social phobia that include social skill deficits are based on the notion that continued social avoidance actively prohibits the development of adequate social skills, particularly because social phobia is an early onset disorder. For example, in one study, Turner and colleagues (1986) found that $85 \%$ of a sample of social phobics reported some form of consistent social avoidance. Among child populations, studies examining the syndrome of social phobia in children as young as 6 years of age have reported links between social avoidance, impairment in social functioning, and the presence of social skill deficits (Beidel, Turner, \& Morris, 1999; Ginsburg, LaGreca \& Silverman, 1998).

In sum, Clark and Wells (1995) propose that cognitive bias, and in particular, the experience of negative self-imagery within social situations, serves to both generate and maintain social phobia over time. In fact, several investigators have found a high frequency of negative self-imagery among social phobics within social settings. However, this research has been associated with numerous limitations, including the use of retrospective report, the sole use of clinical samples of adult 
social phobics, as well as other methodological confounds. Meanwhile, other research has focused on biological factors, social avoidance and skill deficits in generating and maintaining the disorder over time. Overall, at the current juncture, it is necessary that research address these issues through the use of experimental manipulation techniques, such that etiological factors may be partitioned from potential diagnostic outcomes. 


\section{Chapter 3: Clinical Features of Childhood Social Phobia}

The cognitive features of adult social phobia have been studied for some time (e.g., Beidel, Turner, \& Dancu, 1985; Foa, Franklin, Perry \& Herbert, 1996; Rapee \& Lim, 1992). Overall, most researchers believe that the presence of negative thoughts and self-imagery assists in maintaining the emotional distress associated with the disorder. Comparatively however, research examining the cognitive features of childhood social phobia has only begun to accumulate. Although empirical data continue to surface (e.g., Bogels \& Zigterman, 2000; Chansky \& Kendall, 1997; Kendall \& Chansky, 1991; Spence, Donovan, \& Brechman-Toussaint, 1999), results from these investigations have produced less robust findings than are commonly found within the adult literature (see Alfano, Beidel, \& Turner, 2002 for a review). This review updates and extends prior reviews by examining the evidence for the following phenomena among socially-phobic children/adolescents: negative cognition and self-imagery during social situations, negative social expectancies, and performance/social skill deficits. Where empirical findings based on samples of socially-phobic youth are not available or are relatively limited, relevant findings from the adult literature are reviewed.

\subsection{Negative Self-Imagery}

To date, no study has specifically examined negative self-imagery among socially-anxious youth. Recently, however, Hirsch and colleagues (2003) asked 16 socially-phobic adults to hold both negative and neutral self-images in mind during 
two separate social interaction tasks. Following each of the interactions, participants and blind observers completed a questionnaire that assesses observable aspects of performance and anxiety. Results indicated that holding a negative image in mind while engaged in a social interaction elicited significantly higher state and general anxiety ratings. Also, both participants and blind observers rated social phobics in the negative imagery condition as appearing more anxious and showing fewer positive behaviors (e.g., appearing confident and self-assured) than those in the neutral imagery condition. Although social phobics in the negative self-imagery condition rated themselves as evidencing more negative behaviors, observers did not report any differences in negative behaviors (e.g., appearing uncomfortable and awkward) across the two conditions.

Although these findings appear to provide preliminary support for negative self-imagery as a contributing factor in increasing social anxiety, the fact that social phobics rated themselves more negatively than blind observers irrespective of their assignment to an imagery condition would suggest pre-existing levels of anxiety to be a central factor in maintaining social anxiety over time. Additionally, as discussed above, manipulation of negative self-imagery among clinical patients already presumed to experience such imagery does not allow for a determination of whether such phenomena may be a consequence rather than an origin of the disorder. In fact, based on the fact that fear of negative attention and poor social-performance are core features of the disorder, social phobics would be expected to report an increase in anxiety while engaged for 3 to 4 minutes in a negative self-imagery task related to a social setting. In fact, an increase in anxiety might be expected to occur whether the 
individual was faced with an actual anxiety-provoking social situation or not (e.g., imaginal exposure). Finally, it is not clear whether social phobics in the negativeimagery condition may have been more anxious primarily as a result of not being able to completely focus on the actual task.

Hackmann, Surawy and Clark (1998) investigated spontaneously occurring images among adult social phobics and non-patient controls using a structured interview. Overall frequency comparisons of retrospective spontaneously occurring imagery prior to or during anxiety-producing social situations revealed that social phobics experienced greater amounts of spontaneously occurring images than did control subjects. Unfortunately, the fact that socially-phobic participants reported a greater amount of self-imagery during anxiety provoking social situations is confounded by the fact that, by definition, social phobics experience a greater number of anxiety-provoking social situations than non-anxious controls. Moreover, even without controlling for the number of anxiety-provoking social situations encountered, examination of frequency ratings for self-images revealed a mean difference of less than 1 image between the groups. While found to be statistically significant, the clinical significance of this difference is less clear.

In another study, Hackmann, Clark and McManus (2000) explored mental imagery in among 22 adult social phobics through the use of a semi-structured interview. All participants reported experiencing recurrent images during previous social situations, and an additional clinician rated the emotional valence associated with each of these images to be negative in nature. Additionally, most social phobics reported a specific memory that they believed to be directly linked to their individual 
recurring images. In many cases, recurrent images appeared to be more detailed elaborations of a particularly traumatic experience, such as being embarrassed in front of a group, showing overt signs of anxiety, or being criticized during childhood or adolescence. There was also a strong association between the occurrence of these negative experiences and the onset of social phobia, with more than half of participants reporting that they were not socially-anxious prior to the events depicted in their reported self-imagery.

In summary, a small number of studies have reported a high frequency of negative self-imagery among social phobics during social situations. Most of these studies have relied on retrospective reports in establishing the presence of such selfimagery. However, the use of retrospective report in examining self-imagery is subject to well-documented biases in recall. For example, Coles, Turk and Heimberg (2002) examined perspective (observer vs. field) of self-imagery following both a speech and a social interaction task among socially-phobic and non-anxious subjects. Participants were asked to give perspective ratings for self-imagery both immediately following these tasks and at a 3-week follow-up assessment. While social phobics viewed both the social interaction and the speech task from a neutral perspective (neither observer nor field-based) immediately following the task, this group reported a predominantly observer-based perspective for both tasks at 3-week follow-up. Additionally, no differences in the frequency of self-imagery were reported between the two groups. These findings lend support to concerns regarding the frequent use of retrospective report in examining self-imagery and illustrate the point that delayed- 
recall of imagery does not necessarily correspond with actual in-situation experiences.

Overall, there currently is little empirical evidence indicating that negative self-images are actually experienced during social situations and not simply when social phobics are later asked to recall social events. Even if negative self-imagery does occur within actual social settings, it is not clear whether these cognitive events may act as amplifiers of pre-existing heightened levels of anxiety or as causal factors that increase anxiety and decrease performance. One recent study has attempted to elucidate the nature of this relationship based on the use of manipulated self-imagery among socially-phobic adults (Hirsch et al., 2003). However, this approach appears to be potentially problematic based on this groups' high level of susceptibility to increased negative attention and the possibility of poor social-performance. At the current juncture, research is needed to conclusively establish whether negative selfimagery plays a causal role in generating/maintaining social phobia over time.

\subsection{Negative Cognition}

Currently, it is not clear whether socially-phobic children experience similar cognitive phenomena as their adult counterparts (i.e., negative social expectancies, cognitions and self-imagery). Findings to this end have been somewhat mixed. For example, Spence and colleagues (1999) examined cognitive content in relation to a social-evaluative task among both socially-anxious and normal children. Results of a video-mediated recall procedure following the task revealed that socially-phobic children reported a significantly greater number of negative cognitions compared to 
their non-anxious peers. However, using a verbal thought-listing procedure, Beidel (1991) also assessed cognition among socially-phobic, overanxious, and normal control children following a social-evaluative task. Overall, both anxious and nonanxious children reported few thoughts, and no significant differences were found for the types of cognitions reported among the three groups of children. Muris, Merckelback and Damsma (2000) also examined negative cognition/emotion among a community sample of socially-anxious children using several ambiguous stories of social situations. Results indicated that compared to non-anxious children, sociallyanxious children reported a greater frequency of negative cognition in response to the ambiguous stories.

More recently, Alfano, Beidel and Turner (2005) examined the content of cognition among socially-phobic and normal control children during two social tasks involving a same-aged peer. Content of cognition was assessed using a videomediated recall procedure immediately following a social interaction and a read-aloud task and thoughts were later coded by raters blind to the diagnostic status of the children. Results revealed that during the social interaction task, socially-phobic youth reported a greater frequency of negative thoughts related to their performance than control children. However, examination of the actual number of thoughts reported indicated that on average, socially-phobic youth reported one-quarter of one thought. In other words, approximately 20 percent of socially-phobic youth reported experiencing a negative performance thought during the social interaction task. Further, analyses based on level of development revealed that all of these thoughts were reported by socially-phobic adolescents (ages 12 to 17 years) as opposed to 
younger socially-phobic children (ages 7 to 11). No differences in content of cognition were found between diagnostic groups for the read-aloud task.

Using a sample of DSM-III-R Overanxious (OAD), Avoidant (AVD), and Separation-anxious (SAD) children, Chansky and Kendall (1997) examined children's thoughts prior to a social interaction task with peers. Thoughts were coded according to both content (related to social-evaluation or the activity itself) and valence (negative, positive or neutral). Results indicated that compared to nonanxious children, anxious children reported more negative thoughts overall. However, analyses examining the actual content of these negative thoughts revealed nonsignificant differences. Thus, although anxious children were more likely to report negative thoughts, these thoughts did not necessarily pertain to the children's evaluation of their own performance or the interaction itself. Analyses of differences between diagnostic subgroups (OAD vs. AVD vs. SAD) did not reveal any significant findings. It should be noted that although no children in this sample were diagnosed with social phobia (under DSM-III-R), more than two-thirds met criteria for either OAD or AVD, indicating that significant social concerns and/or anxiety were likely present among this subgroup of children.

Other studies also have examined self-reported cognition using heterogeneous samples of anxiety-disordered youth. Bogels and Zigterman (2000) examined dysfunctional cognitions among children and adolescents diagnosed with separation anxiety, social phobia, or generalized anxiety disorder. Anxious children were compared to both normal children and children with a DSM-IV externalizing disorder. The children gave both open and closed-ended responses to 9 ambiguous 
stories (concerning separation, social, and generalized anxiety situations). With respect to types of cognitions, no group differences were found for positive cognitions. Clinically-anxious children reported significantly more negative cognitions than children with externalizing disorders, but not more than normal children. In another investigation, Kendall and Chansky (1991) used a thought-listing procedure to examine differences in cognition between anxious and non-anxious children prior to and while giving a speech. Anxious children reported more negative cognitions than normal controls prior to giving the speech (anticipatory thoughts) but there were no group differences in the frequency of negative thoughts when the children were most nervous (during the task). Accordingly, these data would suggest that the timing of the assessment is an important factor that could lead to different conclusions regarding the presence of negative thoughts in the clinical presentation of childhood anxiety. With respect to specific types of thoughts, $50 \%$ of the anxious children and $60 \%$ of the non-anxious children reported at least one negative thought. When all children who participated in the assessment were included in the analysis (i.e., several children did not report any thoughts), the percentage of children reporting negative cognitions during the task deceased to $34 \%$ of anxious and $30 \%$ of normal control children. Finally, no child reported positive thoughts when most nervous, and $38 \%$ of anxious children and $44 \%$ of non-anxious children denied the presence of any thoughts at all.

In summary, although many researchers propose greater amounts of negative cognition to exist among socially-anxious children, currently, there is insufficient evidence to suggest that negative cognition plays a central role in social phobia 
among youth. Specifically, based on existing research it is unclear whether sociallyanxious children may experience greater amounts of negative cognition in relation to their own performance. Although preliminary findings from Alfano et al. (2005) suggest that level of development may play an important role in the presentation of negative cognition among socially-phobic in youth, in that negative cognition may be more likely at later stages of the disorder's development, these results await replication. Moreover, existing data do not clearly indicate that negative thoughts take place while children are actually engaged in a social-evaluative task. Overall, the results of these studies have produced inconsistent findings warranting further investigation into the potential role of negative cognition in childhood social phobia.

\subsection{Social Expectation}

According to cognitive models of anxiety, socially-phobic individuals experience anxiety and negative self-thoughts within social settings in part, because they possess fundamentally negative social expectancies regarding their own performance and social outcomes (e.g., Rapee \& Heimberg, 1997). Indeed there has been considerable evidence to support the presence of negative social expectations among socially-phobic adults (Lucock \& Salkovskis, 1988; Rapee \& Lim, 1992;

Stopa \& Clark, 1993). Currently however, the exact role of negative social expectancies in social phobia remains unclear. For example, it is not fully understood whether such expectations may lead to clinically-significant levels of social anxiety or rather, represent an eventual outcome following multiple negative social experiences. In accordance with the latter view, negative social expectations have 
been proposed to reflect realistic perceptions of one's abilities following a history of poor performances within social settings. Specifically, continued social avoidance combined with a resulting lack of opportunity to develop adequate social skills has been found impede social performance and trigger negative expectations regarding social outcomes (e.g., Turner, Beidel, Cooley, Woody \& Messer, 1994).

Others have challenged the notion that negative social expectancies reflect accurate perceptions of social phobics' performance (Clark \& Well, 1995; Rapee \& Heimberg, 1997). In particular, Clark and Wells (1995) propose that because sociallyanxious individuals are so focused on how they are being viewed by others, they tend to exaggerate all aspects of their appearance/behavior that might be viewed as negative. Empirical evidence indicating that social phobics do not necessarily perform more poorly than non-anxious individuals or show specific social skill deficits has been cited in support of this view (Rapee \& Lim, 1992). For example, Rapee and Lim (1992) noted that socially-phobic adults make global, rather than specific attributions about their performance and abilities compared to non-anxious individuals. Alden and Wallace (1995) similarly reported that adult social phobics tend to appraise their performance based less upon actual behaviors and more generally on global beliefs about their social inadequacy. In one study comparing social phobics to non-anxious controls, the authors noted that socially-phobic subjects attributed their poor performances during a behavioral task to a general lack of social skill and an inability to cope, rather than the use of specific social behaviors.

However, several studies have identified specific social skill deficits among many socially-phobic individuals (Beidel, Turner \& Dancu, 1985; Heimberg, Hope, 
Dodge \& Becker, 1990; Turner, Beidel \& Townsley, 1990; see social skills section). Further, although Clark and Wells' (1995) model proposes that social phobics are primarily focused on others' perception of them within social settings, there is some evidence to indicate that this may not be the case. In one study by Stopa and Clark (1993), 12 social phobics, 12 patients with other anxiety diagnoses, and 12 normal controls were compared on measures of thought content and attention during a conversational task. Contrary to other data supporting an excessive focus on others' perceptions, results did not reveal any differences between the three groups in terms of their perceptions regarding others' evaluation of their performance.

The majority of studies cited above involving social expectancies have been conducted with samples of adult social phobics. Although research using child/adolescent samples has been relatively limited, available empirical evidence examining expectation of performance among anxious youth in general indicates that these children tend to expect to less positive outcomes than normal children during anxiety-provoking situations. For example, Spence and colleagues (1999) examined expectation of performance and expected probability of social outcomes among a clinical sample of socially-phobic children and normal controls. Results revealed that socially-phobic children were less likely to expect positive outcomes to occur than were control children, though the two groups did not significantly differ in terms of their expectations of negative outcomes. In terms of their own performance, sociallyphobic children expected to perform less well on both a role-play and read-aloud task. Interestingly however, when self-ratings of actual performance were made 
immediately following the two tasks, the groups did not differ based on their selfevaluated performance on either task.

Using a similar method, Alfano, Beidel and Turner (2005) also examined expectation of performance and actual self-rated performance among a group of socially-phobic and normal control children in relation to two social tasks. Results from this investigation revealed that although socially-phobic youth expected to perform worse during the social interaction task, the two groups did not differ in terms of their expectations of performance on the read-aloud task. Similar results were found for ratings of actual performance. Specifically, socially-phobic youth thought they had performed worse than control children during the social interaction task but not the read-aloud task. Although results based on actual performance ratings differ from findings reported by Spence and colleagues (1999), both studies found significantly lower expectations of performance among socially-phobic youth in comparison to non-anxious youth.

Chansky and Kendall (1997) also examined social expectancies prior to a social interaction task, albeit among a sample of differently-diagnosed anxious children and normal controls (ages 9 to 15 years). Results indicated that anxietydisordered children (including children meeting DSM-III-R criteria for overanxious disorder, avoidant disorder, and separation anxiety disorder) endorsed significantly higher levels of negative expectation in anticipation of a social interaction with peers than normal children. Unfortunately, results for specific anxious subgroups were not reported. However, the authors did report that based on the results of a regression analysis, social anxiety, but not social competence, was a significant predictor of 
children's social expectations, despite the fact that anxious children rated themselves as significantly less socially-competent compared to their peers. These results indicate that while anxious children may make negative global attributions about their social competence (e.g., Rapee \& Lim, 1992), social anxiety, as opposed to perceived social-competence, is a more salient factor in understanding lower expectations of performance. Accordingly, although socially-anxious children may perceive themselves as less competent than their peers, differences in expectation of performance may be specifically mediated by differences in level of social anxiety. Of course, this may only be true of performance tasks where socially-phobic children are required to interact with others. For example, another study that required sociallyanxious children (ages 8 to12) to identify the emotional valence of computergenerated faces found that these children expected to perform as well as non-anxious children, though there reaction times were significantly longer (Melfsen \& Florin, 2002).

Overall, limited available research indicates that socially-anxious children are more likely to expect poor performances and greater negative outcomes within social situations. Currently however, it is not clear whether low expectations of performance among socially-anxious youth may be the result of negative self-imagery regarding one's competence, decreased social skills based on continued avoidance, or increased levels of social anxiety during social situations. Along these lines, it also is unclear whether certain social-evaluative tasks are more likely to elicit low expectations of performance among socially-phobic youth. Although it has been specifically proposed that low expectations of performance within social situations in general lead 
to clinically-significant levels of social anxiety (e.g., Rapee \& Heimberg, 1997), research to this end is generally unavailable. Additionally, because a majority of research on expectation of performance has been conducted with adult social phobics, little understanding exists regarding the development and maintenance of low expectations of performance among of socially-phobic children and adolescents.

\subsection{Social Skills}

According to some theorists, social phobics exhibit social skill deficits because continued social avoidance actively prohibits the development of adequate interpersonal skills. In fact, because social phobia is an early onset disorder, this cycle has been discussed in terms of both adult and childhood social phobics. Literature on social withdrawal in childhood suggests that children who do not have adequate social experiences during their formative years may develop social skill deficits due to a lack of socialization. In turn, this lack of socialization is likely to lead to more negative interactions and ultimately, to more socially-inhibited behavior (Rubin \& Mills, 1988). For example, data from a large longitudinal project revealed that social isolation during grade 2 significantly predicted self-rated social incompetence during grade 5 (Hymel et al., 1990). Alternatively, other theorists propose that impeding anxiety, and not inadequate social skills, results in inhibited or decreased performance among socially-anxious individuals (e.g., Juster, Heimberg, \& Holt, 1996). Ironically, according to this view, social phobics perform poorly within social settings mainly because they believe that they do not possess the social skills needed for social 
interaction tasks (Rapee \& Heimberg, 1997). However, both theories postulate that these continued negative social experiences result in further social withdrawal.

Several investigations have found that children with social phobia commonly display deficits in social skills (Alfano, Beidel \& Turner, 2005; Beidel, Turner \& Morris, 1999; Ginsburg, LaGreca \& Silverman, 1998; Spence, Donovan \& Brechman-Toussaint, 1999). In two recent investigations by Beidel and colleagues (Alfano, Beidel \& Turner, 2005; Beidel, Turner \& Morris, 1999), children with social phobia were rated as significantly less skilled by independent observers during both a role-play task and read-aloud task compared to normal control children. In accordance with such deficits, the researchers also found that children with social phobia also had fewer friends, suffered from greater levels of loneliness and avoided extracurricular activities more than their non-anxious peers (Beidel et al., 1999). In a similar study by Ginsburg, LaGreca and Silverman (1998), social avoidance and related impairments in social functioning were apparent in socially-anxious children as young as 6 years of age. Specific findings indicated that socially-anxious children with high levels of social avoidance and distress have more pervasive impairments in social functioning and are more commonly judged by their parents to possess deficits in social skills compared to children with low levels of social anxiety and avoidance.

In a more recent study, Cartwright-Hatton, Hodges and Porter (2003) questioned the notion of social skill deficits and proposed that what appear to be deficits among socially-anxious children may simply be nervous behaviors that do not require remediation through social skills training programs. The authors used a sample of high and low socially-anxious children (ages 8-11 years) asked to give a 2- 
minute impromptu speech task in front of a camera, which they were told would later be viewed by adults. Children (as well as blind observers) were later asked to rate their own behavior during the task based on three domains of performance: microskill behaviors (including voice volume, eye-contact and smiling); nervous behaviors (including looking nervous and stumbling over ones' words); and global impression (including looking clever and friendly, and general quality of the speech).

Correlational analyses indicated that in terms of both children's subjective ratings and observers' objective ratings of performance, only self-ratings of nervous behaviors rose significantly in line with ratings social anxiety. The authors concluded that children with high levels of social anxiety do not necessarily require social skills training. However, several limitations associated with this study are noteworthy. First, because a non-clinic population of children was used, conclusions that may be drawn are somewhat limited. It is also important to note that a 2-minute speech task, as opposed to a task requiring more social interaction, may not be as useful for assessments of social skill among young children.

Spence and colleagues (1999) examined social skills among 27 sociallyphobic children and a matched sample of non-anxious children (ages 7 to 14). Social skills were assessed in a number of ways including child and parent report on questionnaires, direct observation in a naturalistic setting (i.e., school) and behavioral observation during a structured role-play task. Results revealed that socially-phobic were less socially-skilled than their peers as rated by both themselves and their parents. Based on observer-rated social behaviors at school, socially-phobic children were significantly less likely to interact with peers and initiated fewer social 
interactions than the control group of children, indicating a significant degree of social avoidance to be present. During the role-play task, socially-phobic children responded with fewer words but did not differ from control children in terms of their eye-contact or the latency of their responses. While some studies from the adult literature have reported different findings with regard to eye-contact and latency of responses (Beidel, Turner \& Dancu, 1985; Heimberg, Hope, Dodge \& Becker, 1990; Turner, Beidel \& Townsley, 1990), this finding indicates that among socially-phobic youth it may be the quality of these children's responses (as opposed to the frequency of nervous behaviors) that commonly result in lower ratings of social skill. Overall results from this study are consistent with a model of social phobia including considerable social avoidance and resulting social skill deficits as important factors in maintaining social anxiety. Nonetheless, because other studies (Cartwright-Hatton, Hodges \& Porter, 2003) have focused on nervous behaviors as opposed to actual skill deficits, more research is needed to disentangle this issue. 


\section{Chapter 4: Implications for the Current Study}

It is apparent that, to a large extent, recent interest in the cognitive phenomena associated with social phobia has been fueled by Clark and Wells' (1995) cognitive model of the disorder. Central to this model is the notion that reoccurring negative self-images lead to increased anxiety, further cognitive biases, and decreased social performance within social settings. To date, several studies have found sociallyphobic adults to experience a greater amount of spontaneously occurring negative images within social settings compared non-anxious persons. However, most of these studies have relied on retrospective report in establishing the presence of selfimagery. Thus, although available data suggest some relationship to exist between negative self-imagery and social anxiety, the nature of this association is unclear at this time. For example, although negative self-imagery may play a causal role in the onset of social phobia, it also is possible that negative-self images represent a longterm consequence of heightened anxiety within social settings and that ineffectual social performances/skills are the result of an extant history of social avoidance (resulting in more fundamental social skill deficits). In order to fully understand the relationship between social anxiety, cognition, social performance and negative selfimagery, experimental control over these variables is necessary. However, as reviewed above, the manipulation of self-imagery among socially-phobic individuals is problematic in that studies limited to the assessment of clinical subjects may incorrectly reveal the consequences of a disorder rather than its' origins (Sher \& 
Trull, 1996). Thus, the use of experimental manipulation among normal subjects is needed, such that etiological factors may be partitioned from diagnostic outcomes. Another limitation of this research is represented by the fact that the average age of onset for social-phobia occurs during adolescence. As such, it is reasonable to assume that many adult social phobics have suffered from the disorder for a good portion of their lives and thus, cognitive distortions or negative biases (including negative self-images) may be well developed in these individuals based on an extant history of negative social performances and outcomes. In order to best understand the role of negative self-imagery in social phobia, examination during the period which onset of the disorder is most likely, namely adolescence, is needed. Adolescence, a period marked by physical, social and cognitive changes, has been associated with increased self-consciousness and awareness of the evaluation of others (Bruch, Giordano, \& Pearl, 1986). It is not surprising therefore, that this period commonly corresponds with the onset of social phobia. An increase in self-consciousness and awareness of others' perceptions may be a specific trigger for increased social fears. Although research to this end has been relatively limited, examination of negative self-imagery and its relationship to social anxiety, cognition, social expectation and social performance among non-anxious adolescents will allow for a better understanding of the development of social phobia in youth.

Based on the limitations of previous research, the current investigation utilized a methodological approach aimed at clarifying the potential role of negative self-imagery in social phobia. By manipulating self-imagery among a group of nonanxious adolescents during two social-interactional tasks, results from this study will 
hopefully allow for a better understanding of the unique role of self-imagery during the period of the greatest onset of social phobia. Based on suggestion and findings from adult studies, self-imagery utilized in the current study was tailored to each adolescent's unique social experiences. Specifically, in order to ensure emotional salience, negative self-images were generated by the adolescents themselves (with assistance as needed) and related to a recent negative social experience where the adolescent was embarrassed, nervous, or performed poorly in front of others. Nonanxious adolescents asked to engage in self-imagery were compared to sociallyphobic and control adolescents on measures of anxiety, cognition, social expectation, and performance and specific measures of social skill. Findings from this investigation have the potential to inform the development of future models of social anxiety, directions for experimental research, and most importantly, future treatment efforts. 


\section{Chapter 5: Method}

\subsection{Subjects}

\subsubsection{Patient sample}

The patient sample consisted of 21 adolescents with a primary diagnosis of DSM-IV social phobia (generalized subtype) referred for treatment at the Maryland Center for Anxiety Disorders (MCAD) at the University of Maryland in College Park, Maryland. Adolescents were referred by school counselors, physicians, other professionals, or their parents responded to advertisements regarding free treatment for "shy" children. All socially-phobic adolescents were enrolled in regular classes. Because adolescents with social phobia often have comorbid anxiety and depressive disorders (Beidel, Turner \& Morris, 1999), such adolescents were also included in the study. However, socially-phobic adolescents with comorbid depressive disorders were included only if their depressive symptoms were determined to be mild to moderate as opposed to severe (as defined by ADIS-C severity ratings and total CDI score). Adolescents with other disorders (e.g., psychotic disorders, eating disorders, conduct disorder, substance-abuse disorders, and bipolar disorder) were excluded from participating in the study and provided with appropriate referrals within the local community.

Mean age for the socially-phobic adolescents was 14.05 years $(\mathrm{SD}=1.56)$ with a range of 12 to 16 years. Twelve subjects $(57 \%)$ were male. There were $13(62 \%)$ Caucasian and 8 (38\%) African-American adolescents in the patient sample. Sixtyseven percent met diagnostic criteria for one comorbid diagnosis and $19 \%$ met diagnostic criteria for two comorbid diagnoses. Diagnoses included generalized 
anxiety disorder (29\%), ADHD (19\%), separation anxiety disorder (10\%), depression (10\%), dysthymia (10\%), specific phobia (5\%), and selective mutism (5\%).

\subsubsection{Self-Imagery and Control Adolescents}

Normal adolescents were recruited as "peer-helpers" for the treatment program described above and were randomly assigned to one of two groups: a control group or an experimental self-imagery group (IMAG). Both groups consisted of twenty-one adolescents each for a total of 42 normal adolescents. Normal adolescents did not meet DSM-IV criteria for any Axis I disorder. Normal adolescents also were screened for any sub-threshold depressive symptoms using a self-report measure (the CDI) and were excluded from the study if they reported any significant depressive symptomatology.

Mean age for control adolescents was 13. 29 years $(\mathrm{SD}=1.2)$ and 13.43 $(\mathrm{SD}=1.2)$ for IMAG adolescents, with an age range of 12 to 16 years. For the control group, eight (38 \%) adolescents were male. There were 12 (57\%) Caucasian and 9 (43\%) African-American adolescents in control sample. For the IMAG group, 11 (52\%) adolescents were male. Nine (43\%) Caucasian, 11 (52\%) African-American, and 1 (5\%) adolescent of mixed/other ethnicities comprised the self-imagery sample.

\subsection{Assessment}

\subsubsection{Diagnostic Interview}

All adolescents and their parents were interviewed either by a licensed clinical psychologist, a post-doctoral fellow or an advanced doctoral student using the Anxiety Disorders Interview Schedule for Children for DSM-IV (ADIS-C; Silverman 
\& Albano, 1996). Silverman, Saavedra and Pina (2001) recently reported adequate test-retest reliability for the ADIS-C anxiety disorders categories. For the current investigation, diagnoses were determined by the clinician on the basis of information provided by both the child and the parent during separate interviews.

\subsubsection{Self-Report}

Social Phobia and Anxiety Inventory for Children (SPAI-C). The SPAI-C (Beidel, Turner, \& Morris, 1995) is a self-report measure designed to assess social fears in youth. The 26-item instrument assesses potentially fearful social situations, including physiological, cognitive, and behavioral reactions. For each item, children are given 3 choices from which they select the one that best describes how they feel/think/behave in different social situations. The SPAI-C has been shown to be a valid and reliable measure of childhood social phobia (Beidel, Turner, Hamlin, \& Morris, 2000).

Children's Depression Inventory (CDI): The CDI (Kovacs, 1985) is the most widely-used self-report depression inventory for children and adolescents and has been shown to be a valid and reliable measure of depression in youth (Kovacs, 1981). The 27-item measure includes several sub-scales including scales to measure negative mood, anhedonia, negative self-esteem and ineffectiveness. For each item, children are given 3 choices from which they select the one that best describes how they have felt over the previous 2 weeks.

Ratings of anxiety: Following the role-play and the read-aloud tasks, all adolescents were asked to rate their level of anxiety using a 5-point likert scale, with a 
1 reflecting very little to no anxiety and a 5 reflecting extreme anxiety. Ratings were kept private from the confederate peer.

Expectation/Performance: Immediately prior to each behavioral task (but following task directions), all adolescents completed a 4-item questionnaire regarding expectations of their performance. Questions assessed adolescents' expectation of their 1) overall performance on the tasks, 2) ability to hide their anxiety, 3) use of task-specific skills, 4) and their peer's evaluation of their performance. Each question was rated on a 4-point likert-type scale where 1=poorly, 2=somewhat poorly, $3=$ somewhat well, and 4=well. Thus, for each task a maximum total score of 16 was possible. For the role-play task, the expectation questionnaire was administered following a practice scene to ensure that the adolescents understood the task's requirements. Immediately following both tasks, adolescents were asked to complete a similar 4-item questionnaire regarding how well they thought they actually performed on the previous task. Items on the performance questionnaires matched items on the expectation questionnaires, but were worded in the past tense. Adolescents' responses were based on the same 4-point likert-type scale. Although peers were present in the room at the time these questionnaires were completed, they were unable to see the adolescents' ratings of their expectation/performance.

Integrity of Self-Imagery: Following all three behavioral tasks (described below), adolescents in the IMAG group completed a questionnaire assessing the degree to which they were able to engage in self-imagery during each task. The questionnaire used a 4-point likert scale (1=not at all/a little bit, 2=somewhat, $3=$ most of the time, $4=$ all the time) and ratings were made for each of the three tasks 
separately. Of note, any task receiving a self-imagery integrity rating $=1$ was excluded from the final analyses.

\subsubsection{Behavioral Assessment}

All adolescents participated in two laboratory tasks ( 5 role-play scenes with another adolescent and reading an age-appropriate story aloud) designed to measure both social skill and anxiety. Order of the role-play and read-aloud tasks was randomized for all subjects and adolescents were informed that they could discontinue the tasks at any time. All adolescents chose to participate in both behavioral tasks. Prior to the behavioral assessment, the IMAG group of adolescents was instructed to engage in self-imagery during the two tasks. This sub-group of adolescents also participated in a third interactional task in order to ensure that there were no lasting effects from the imagery task (see Procedures Section). Following the laboratory tasks, a video-mediated recall procedure designed to assess negative/positive cognitions was conducted. All procedures are described in detail below.

Social Interaction Task: All adolescents engaged in 5 role-play scenes requiring interaction with a same age peer. For the social interaction task, assessors provided a brief description of a social situation including both the subject and the peer helper (e.g., sitting next to one another in class). For each individual role-play, peer helpers were prompted to direct two separate statements toward subjects using

standardized cue cards. Subjects were instructed to respond to the peer as they would if they were actually in that situation (i.e., including instances where they would not respond to their peer). Role-play scene content included carrying on a conversation, 
giving a compliment, receiving another adolescent's offer for help, receiving a compliment, and requesting that another child change their behavior.

Performance Task: All adolescents were asked to read-aloud an ageappropriate story (“The Ransom of Red Chief” by O. Henry) for 10 minutes in front of the assessor and the same peer used for the role-play task.

Additional Social Interaction Task: Adolescents in the IMAG group (only) engaged in 5 additional role-play scenes requiring interaction with the same peer at the end of the behavioral assessment. Procedures for and content of these role-play were similar to the first role-play task and are described below.

\subsection{Video-Mediated Recall of Cognition}

Following the role-play and the read-aloud tasks, peers were asked to leave the room while the adolescents viewed a videotape of the tasks they just performed. The videotape was stopped four times (twice during the role-play and twice during the read-aloud tasks) and adolescents were asked to retrospectively recall their thoughts at each point on the videotape. For the role-play task, all subjects viewed the first two role-plays performed and the tape was paused after each. For the read-aloud task, the tape was paused both one minute and three minutes into the reading. Specific stop points were chosen arbitrarily but allowed for children to view an ample portion of each task prior to recalling their specific thoughts. Thoughts were recorded verbatim by the assessor and later coded by blind raters. For the current investigation, a videotape shot from the child's perspective was used based the findings and suggestion of previous research (Lodge, Tripp \& Harte, 2000) that this perspective 
may assist children in retrospectively recalling their thoughts. Additionally, based on previous questions raised with regard to the importance of camera position for use with video-mediated recall procedures (e.g., Schwartz \& Garamoni, 1986), Lodge, Tripp and Harte (2000) also compared children's self-reported cognitions based on two separate camera positions: one from the observer's perspective and one from the child's perspective. Overall findings from these studies revealed that the child's perspective video-mediated recall procedure produced the greatest amount of child reported cognitions. Thus, for the current investigation a child's perspective videomediated recall procedure immediately following a behavioral task was used.

\subsection{Procedures}

All adolescents and their parents signed consent/assent forms providing details of the study. For the current investigation, ADIS-C interviews were conducted by advanced doctoral students in clinical psychology or doctoral level psychologists. All interviewers were experienced in conducting diagnostic interviews using the ADIS-C/P. The presence of diagnoses was determined by the clinician on the basis of information provided by both the adolescent and the parent/legal guardian during separate interviews and based on the self-report instruments. In order to ensure interrater agreement for ADIS-C diagnoses, twenty-five percent of interviews were videotaped and rated by a second clinician blind to the diagnostic status of the adolescent. The interrater reliability (kappa coefficient) for a diagnosis of social phobia was adequate $(k=.85)$. If it was determined that the adolescent met criteria for 
a psychiatric diagnosis, the parent/guardian was given a referral for treatment by a member of the MCAD staff.

If exclusion criteria were not met, adolescents were asked to participate in the behavioral tasks as described above. All behavioral tasks were videotaped and later rated by independent raters blind to the diagnostic status of subjects. Independent raters used similar likert-type anxiety and performance scales as used by the adolescents. All raters were trained in using behavioral ratings prior to rating videotapes. Twenty-five percent of the videotapes were then rated independently by a second rater in order to ensure inter-rater reliability for all ratings. Inter-rater reliability (Pearson's $r$ ) was $r=.85$ for anxiety, $r=.89$ for overall performance and $r=.90$ for specific social skills.

Table 2. Cognition Coding Categories

\begin{tabular}{|l|l|}
\hline Cognition Category & Definition \\
\hline Negative Performance & $\begin{array}{l}\text { Thoughts specifically related to the child's performance that are } \\
\text { negative in nature. Example: "I really messed that up!" }\end{array}$ \\
\hline Neutral Performance & $\begin{array}{l}\text { Thoughts specifically related to the child's performance that are } \\
\text { neither positive nor negative. Example: "I wonder how you } \\
\text { pronounce this word." }\end{array}$ \\
\hline Positive Performance & $\begin{array}{l}\text { Thoughts specifically related to the child's performance that are } \\
\text { positive in nature. Example: "I am a good reader." }\end{array}$ \\
\hline Negative Task & $\begin{array}{l}\text { Thoughts specifically related to the task that are negative in } \\
\text { nature. Example: "This is boring." }\end{array}$ \\
\hline Positive Task & $\begin{array}{l}\text { Thoughts specifically related to the task that are neither positive } \\
\text { nor negative. Example: "Something like that happened to me } \\
\text { once." }\end{array}$ \\
\hline Other & $\begin{array}{l}\text { Thoughts specifically related to the task that are positive in } \\
\text { nature. Examples: "I like this story." }\end{array}$ \\
\hline & $\begin{array}{l}\text { Thoughts that are unrelated to the child's performance or the } \\
\text { task. Example: "I want pizza tonight." }\end{array}$ \\
\hline
\end{tabular}

During the video-mediated recall procedure, thoughts were recorded verbatim by the assessor. Independent raters later coded self-reported thoughts into 1 of 7 
categories based on both valence (negative, neutral or positive) and content (performance-based, task-related, or off-task). See table 2 for a full description of coding categories. The raters were trained so that inter-rater reliability was at least .80 (Cohen's kappa) for each cognition category. Twenty-five percent of all cases were then rated independently by a second rater to ensure inter-rater reliability for cognition ratings.

\subsubsection{Manipulation of Self-Imagery}

During both the first role-play and read-aloud tasks, adolescents in the IMAG group were asked to engage in the same type of negative self-imagery believed to exist among social phobics during social situations. Specifically, adolescents were asked to recall a specific social experience/event where they felt embarrassed, foolish, awkward, etc. Adolescents were assisted in recalling an experience/event and/or choosing an appropriate negative social experience as needed. The most common examples of negative self-images included giving the wrong answer in class, making a mistake during a performance (e.g., while playing a sport) and doing something clumsy in public (e.g., dropping something). Once an experience/event was chosen, adolescents were asked to hold this image of themselves in their minds during both the first role-play task and the read-aloud task. A red light was used to cue the use of negative self-imagery and to remind adolescents to use the image throughout the tasks.

Following the first set of role-plays, read-aloud task, and video-mediated recall of cognition, adolescents in the IMAG group (only) were asked to perform 5 additional role-plays with the same peer. However, for the second set of role-plays, 
IMAG adolescents were asked to engage in positive self-imagery. Examples of positive self-imagery were provided and assessors assisted the adolescents in identifying a social experience/event where they felt smart, looked cool, did/said the right thing, etc. The most common examples of positive self-images included receiving a compliment from a peer, scoring the team-winning goal, and answering questions correctly in class. Once an experience/event was chosen, adolescents were asked to hold this positive self-image in their minds during the final set of role-plays. While engaged in the positive self-imagery task, a blue light was used to prompt and remind adolescents to begin, continue, and discontinue using imagery. Although the positive self-imagery task was included for the main purpose of minimizing any potential effects following the negative self-imagery task, IMAG adolescents were asked to rate their anxiety following this task. Finally, self-imagery integrity ratings were made by the adolescents immediately following all three behavioral tasks. 


\section{Chapter 6: Results}

\subsection{Preliminary Analyses}

\subsubsection{Demographics}

Chi-square and T-tests were used to examine possible demographic differences between socially-phobic, self-imagery, and control adolescents. There were no significant group differences in terms of age, gender or race. Specific means and standard deviations can be found in table 3 .

\section{Table 3. Demographic Characteristics}

\begin{tabular}{|l|c|c|c|l|}
\hline & $\begin{array}{l}\text { Social Phobia } \\
n / M(\% / S D)\end{array}$ & $\begin{array}{l}\text { Self-Imagery } \\
n / M(\% / S D)\end{array}$ & $\begin{array}{l}\text { Controls } \\
n / M(\% / S D)\end{array}$ & $\mathbf{p} / \boldsymbol{X}^{2}$ value \\
\hline Age & $14.05(1.5)$ & $13.43(1.2)$ & $13.29(1.1)$ & .147 \\
\hline Gender & $9(43)$ & $10(48)$ & $13(62)$ & .438 \\
$\quad$ Female & $13(62)$ & $9(43)$ & $12(57)$ & .515 \\
\hline Ethnicity & $8(38)$ & $11(52)$ & $9(43)$ & \\
$\quad$ Caucasian & $0(0)$ & $1(5)$ & $0(0)$ & \\
African-American & Mixed/other & \multicolumn{2}{|c|}{} & \\
\hline
\end{tabular}

\subsubsection{Social Anxiety}

A univariate ANOVA was conducted to examine total SPAI-C scores across the three groups. The overall $\mathrm{F}$ was significant $[F(1,62)=40.01, p<.001]$. As expected, a follow-up tukey's HSD test revealed that socially-phobic adolescents endorsed significantly higher self-ratings of social anxiety $(M=27.6, \mathrm{SD}=12.4)$ than both IMAG $(\mathrm{M}=6.6, \mathrm{SD}=6.2)$ and control $(\mathrm{M}=6.9, \mathrm{SD}=5.8)$ adolescents, while the latter two groups did not differ in terms of their overall levels of social anxiety. 


\subsubsection{Self-Imagery Integrity check}

Overall examination of self-imagery integrity ratings indicated that all adolescents in the IMAG condition were able to hold self-imagery in mind during all three behavioral tasks at least some of the time (i.e., no task received an integrity rating $=1$ for any of the tasks). A separate repeated measure ANOVA comparing self-imagery ratings across all three tasks also was conducted. The result of this analysis did not reveal a significant difference in the adolescents' ability to hold the image in mind across the three tasks. Specifically, integrity ratings indicated that all adolescents utilized self-imagery between "somewhat" and "most of the time" during the negative imagery role-play $(\mathrm{M}=2.6, \mathrm{SD}=.74)$, read-aloud task $(\mathrm{M}=2.6, \mathrm{SD}=.81)$ and positive imagery role-play $(\mathrm{M}=3.0, \mathrm{SD}=.95)$.

\subsection{Performance Anxiety}

Univariate ANOVAs were conducted to examine self-rated anxiety during the role-play and read-aloud tasks. For the role-play task, the overall F was significant $[F(1,62)=24.41, p<.001]$ and follow-up tukey's HSD tests revealed that sociallyphobic adolescents endorsed significantly higher ratings of anxiety $(\mathrm{M}=2.9, \mathrm{SD}=.77)$ than IMAG $(\mathrm{M}=1.86, \mathrm{SD}=.85)$ and control $(\mathrm{M}=1.33, \mathrm{SD}=.58)$ adolescents. Although the IMAG group reported higher levels of anxiety than control adolescents, this result failed to reach statistical significance $(p=.065)$. For the read-aloud task, the overall $\mathrm{F}$ also was significant $[F(1,62)=6.22, p<.01]$. Follow-up tests revealed that sociallyphobic adolescents endorsed significantly higher ratings of anxiety $(M=2.71, S D=1.1)$ 
than the control adolescents $(\mathrm{M}=1.62, \mathrm{SD}=.81)$ but not the $\mathrm{IMAG}$ adolescents $(\mathrm{M}=2.24, \mathrm{SD}=1.1)$. The IMAG adolescents did not differ from either group.

Table 4. Self-reported Anxiety (scale 1-5)

\begin{tabular}{|l|l|l|l|}
\hline & $\begin{array}{l}\text { Social Phobia }^{\mathrm{a}} \\
\mathrm{M}(\mathrm{SD})\end{array}$ & $\begin{array}{l}\text { Self-Imagery }^{\mathrm{b}} \\
\mathrm{M}(\mathrm{SD})\end{array}$ & $\begin{array}{l}\text { Control }^{\mathrm{c}} \\
\mathrm{M}(\mathrm{SD})\end{array}$ \\
\hline Role-play Anxiety & $2.9(.77)^{\mathrm{bc}}$ & $1.9(.85)^{\mathrm{c}^{*}}$ & $1.3(.58)$ \\
\hline Read-aloud Anxiety $_{\mathrm{abc}}=p<.05 ;{ }^{*}=p<.06$ & $2.7(1.1)^{\mathrm{c}}$ & $2.2(1.1)$ & $1.6(.81)$ \\
\hline
\end{tabular}

\subsection{Self-Rated Performance}

\subsubsection{Expected Performance}

In order to control for the experiment-wise error rate, a multivariate analysis of variance (MANOVA) was used to examine overall expectation of performance during the role-play task. The overall $\mathrm{F}$ was significant $[F(1,62)=3.89, p<.001]$. In particular, SOC adolescents expected to perform worse than both IMAG and control adolescents on the role-play task. Additionally, follow-up univariate ANOVAs examining specific aspects of expected performance revealed significant differences for each of the three domains measured by the role-play expectation questionnaire. Significant differences emerged in terms of the adolescents' expectation of their ability to hide their anxiety $[F(1,62)=8.90, p<.001]$, think of things to say to their peer $[F(1,62)=11.91, p<.001]$, and how their peer would judge their performance $[F(1,62)=7.47, p<.001]$. Follow- up Tukey's HSD tests revealed that compared to both the IMAG and control adolescents, SOC youth expected to perform worse across 
each of these domains of performance during the role-play task. The self-imagery and control adolescents did not differ across each domain of expected performance.

A MANOVA used to examine expectation of performance during the readaloud task also revealed an overall significant difference $[F(1,62)=2.35, p<.05]$. Specifically, SOC adolescents expected to perform worse than both IMAG and control adolescents on the read-aloud task. Follow-up univariate ANOVAs examining specific aspects of expected performance revealed significant differences for two of the three domains measured by the read-aloud expectation questionnaire, including the adolescents' expectation of their ability to hide their anxiety $[F(1,62)=7.20$, $p<.01]$ and how their peer would judge their performance $[F(1,62)=7.81, p<.001]$. Follow- up tests revealed that compared to both the IMAG and the control adolescents, SOC youth expected to perform worse across both of these domains during the read-aloud task, while the IMAG and control adolescents did not differ on these items. Additionally, the three groups did not differ in their expectation of their ability to pronounce the difficult words $[F(1,62)=2.55, p=.086]$. See Table 4 for specific expectation scores across the three groups.

\subsubsection{Performance Ratings}

A MANOVA used to examine self-rated performance during the role-play task revealed an overall significant difference $[F(1,62)=3.92, p<.001]$. Overall, SOC adolescents rated their performance worse than both IMAG and control adolescents. Although IMAG adolescents rated their overall performance to be worse than control adolescents, this result failed to reach statistical significance $(p=.07)$. Follow-up univariate ANOVAs examining specific aspects of performance revealed 
significant differences for each of the three domains measured by the role-play performance questionnaire. Significant differences were found in terms of the adolescents' belief that they were able to hide their anxiety $[F(1,62)=11.73$, $p<.001]$, think of things to say to their peer $[F(1,62)=11.27, p<.001]$, and their peer's judgment of their performance $[F(1,62)=5.43, p<.01]$. Follow- up Tukey's HSD tests revealed that control adolescents believed that they were better able to hide their anxiety than both SOC and IMAG adolescents. SOC and IMAG adolescents did not differ in their self-rated ability to hide their anxiety during the role-play task. In terms of the specific ability to generate conversation, SOC youth expected to perform the worst overall, while the IMAG and control groups did not differ from each other. Finally, SOC youth believed that their peers judged their performance to be significantly worse than control adolescents, while IMAG adolescents did not differ from either group.

A MANOVA used to examine self-rated performance during the read-aloud task did not reveal an overall significant difference between the three groups $[F(1,62)$ $=.944, p=.483]$. Thus, read-aloud performance data was not examined further. See Table 5 for specific performance scores across the three groups.

Table 5. Expectation and Self-Performance ratings (scale 0-16)

\begin{tabular}{|l|l|l|l|}
\hline & $\begin{array}{l}\text { Social Phobia } \\
\text { M(SD) }\end{array}$ & $\begin{array}{l}\text { Self-Imagery }^{\mathrm{b}} \\
\mathrm{M}(\mathrm{SD})\end{array}$ & $\begin{array}{l}\text { Control }^{\mathrm{c}} \\
\mathrm{M}(\mathrm{SD})\end{array}$ \\
\hline Role-play Expectation & $10.3(3.1)^{\mathrm{bc}}$ & $13.5(2.5)$ & $14.5(2.1)$ \\
\hline Role-play Performance & $10.4(3.2)^{\mathrm{bc}}$ & $12.8(2.8)^{\mathrm{c}^{*}}$ & $14.6(1.8)$ \\
\hline Read-aloud Expectation & $11.4(2.6)^{\mathrm{bc}}$ & $13.5(2.7)$ & $14.3(2.1)$ \\
\hline Read-aloud Performance & $10.7(3.2)$ & $11.8(2.5)$ & $12.8(3.2)$ \\
\hline $\mathrm{abc}^{\mathrm{ac}}=p<.05 ;{ }^{*}=p<.07$ & &
\end{tabular}




\subsubsection{Expectation versus Actual Performance}

In order to examine changes in expected versus actual performance from pre to post task, two $3 \times 2$ (group $\mathrm{x}$ evaluation period) repeated measure ANOVAs were conducted using total expectation and performance scores from the role-play and read-aloud tasks. For the read-aloud task, a significant main effect for evaluation period emerged $[F(1,62)=25.60, p<.001]$ and is depicted in Figure 1. Examination of mean scores revealed that adolescents across all three groups rated their actual performance to be poorer than their initial expectation for the read-aloud task. No main effect for group or significant interaction effects were detected. On the role-play task, no significant main effects or interactions were detected for evaluation period or group.

Figure 1. Expected vs. Actual Performance on Read-aloud

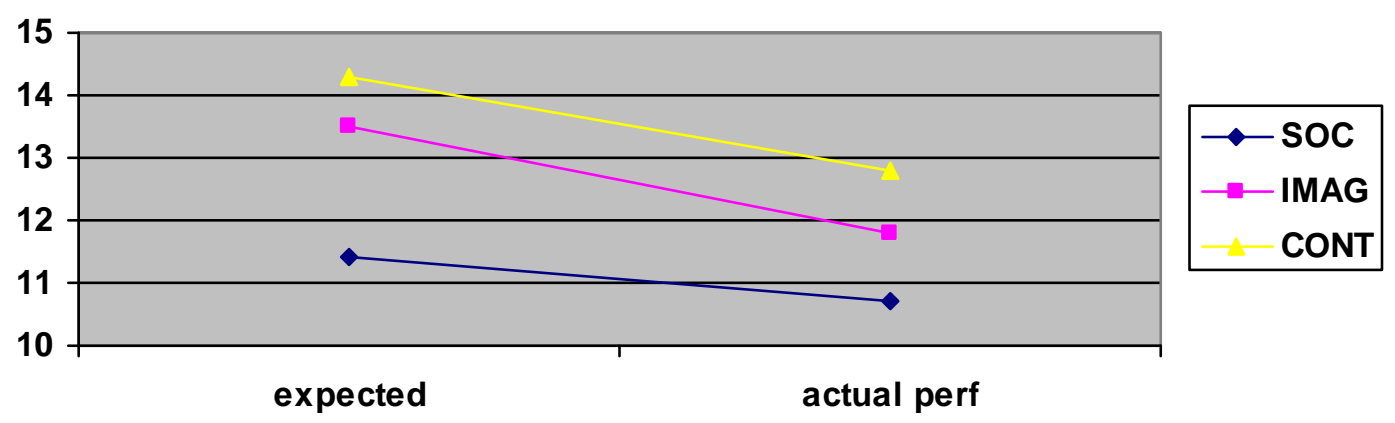

\subsection{Observer Ratings}

\subsubsection{Anxiety}

Two univariate ANOVAs examining observer-rated anxiety during the roleplay and read-aloud tasks were conducted. For the role-play task, the overall $\mathrm{F}$ was 
significant $[F(1,62)=20.64, p<.001]$. Follow-up tukey's HSD tests revealed that SOC adolescents appeared more anxious $(\mathrm{M}=2.7, \mathrm{SD}=.77)$ than both the IMAG $(\mathrm{M}=1.7, \mathrm{SD}=.50)$ and control $(\mathrm{M}=1.7, \mathrm{SD}=.41)$ adolescents during the role-play task. For the read-aloud task, the overall $\mathrm{F}$ also was significant $[F(1,62)=7.56, p<.001]$. Similar to results for the role-play task, follow-up tests revealed that SOC adolescents appeared more anxious $(\mathrm{M}=2.0, \mathrm{SD}=.63)$ than both the $\mathrm{IMAG}(\mathrm{M}=1.4, \mathrm{SD}=.48)$ and control adolescents $(\mathrm{M}=1.5, \mathrm{SD}=.56)$ while reading aloud. The IMAG and control adolescents were judged to exhibit similar levels of anxiety during both tasks.

\subsubsection{Performance}

Univariate ANOVAs examining observer-rated performance during the roleplay and read-aloud tasks were also conducted. For the role-play task, the overall $\mathrm{F}$ was significant $[F(1,62)=29.04, p<.001]$ and follow-up tests revealed that performances by $\mathrm{SOC}$ adolescents were rated as less effective $(\mathrm{M}=2.1, \mathrm{SD}=.62)$ than both IMAG (M=3.3, SD=.70) and control $(\mathrm{M}=3.4, \mathrm{SD}=.52)$ adolescents The performances of IMAG and control adolescents did not differ. For the read-aloud task, the overall $\mathrm{F}$ was not significant $[F(1,62)=2.51, p=.090]$, indicating that the three groups exhibited similarly effective performances.

\subsubsection{Social Skill}

In addition to overall performance ratings, observers were asked to rate discrete areas of social skill, including facial gaze and speech latencies for all subjects during the role-play task. Two univariate ANOVAs were used to examine ratings of social skills across the three groups. For facial gaze, the overall $\mathrm{F}$ was significant $[F(1,62)=6.41, p<.01]$. Follow-up tukey's HSD tests revealed that SOC adolescents 
exhibited appropriate facial gaze with their peer $(\mathrm{M}=.23, \mathrm{SD}=.30)$ less often than both the IMAG $(\mathrm{M}=.62, \mathrm{SD}=.45)$ and control $(\mathrm{M}=.59, \mathrm{SD}=.40)$ adolescents (where a score of 1.0 indicates appropriate facial gaze at all times during the role-play task). For speech latencies, the overall $\mathrm{F}$ also was significant $[F(1,62)=12.17, p<.001]$. Similar to results for facial gaze, follow-up tests revealed that SOC adolescents required significantly more time to reply to their peer $(\mathrm{M}=2.3$ seconds, $\mathrm{SD}=1.7)$ than both the IMAG $(\mathrm{M}=.65, \mathrm{SD}=.77)$ and control adolescents $(\mathrm{M}=.74, \mathrm{SD}=.98)$. The IMAG and control adolescents were observed similarly in terms of these two aspects of social skill.

\subsection{Cognition}

\subsubsection{Data reduction}

Examination of the frequency of thoughts for the 7 original categories revealed that few or no children reported cognitions coded as Positive Performance, Positive Task or Off-task thoughts. Thus, to increase statistical power for subsequent analyses, these categories were eliminated, resulting in a total of 4 cognition categories (including Negative Performance thoughts, Neutral Performance thoughts, Negative Task thoughts, and Neutral Task thoughts). Inter-rater reliability for these categories was excellent. Specifically, resulting Cohen's kappa coefficients were as follows: Negative Performance: $k=.92$, Neutral Performance: $k=.90$, Negative Task: $k=.85$, and Neutral Task: $k=.95$. 


\subsubsection{Total Thoughts}

To examine overall differences in the frequency of thoughts reported between the three groups, univariate ANOVAs examining total number of thoughts reported during the role-play and read-aloud tasks were conducted. Differences in terms of the frequency of thoughts reported by each group during the read-aloud task failed to reach statistical significance $[F(1,62)=2.75, p=.07]$. For the role-play task however, the overall $\mathrm{F}$ was significant $[F(1,62)=3.81, p<.05]$. Follow-up tukey's HSD tests revealed that adolescents in the IMAG group $(\mathrm{M}=1.48, \mathrm{SD}=.98)$ reported significantly fewer thoughts than SOC adolescents $(\mathrm{M}=2.48, \mathrm{SD}=1.4)$, while the control adolescents did not differ from either group $(\mathrm{M}=2.10, \mathrm{SD}=1.1)$. Thus, in order to control for the effect of total frequency of thoughts on specific types of cognitions reported, number of thoughts was entered as a covariate for all subsequent analyses of role-play cognition.

Figure 2. Mean number of reported Cognitions by group

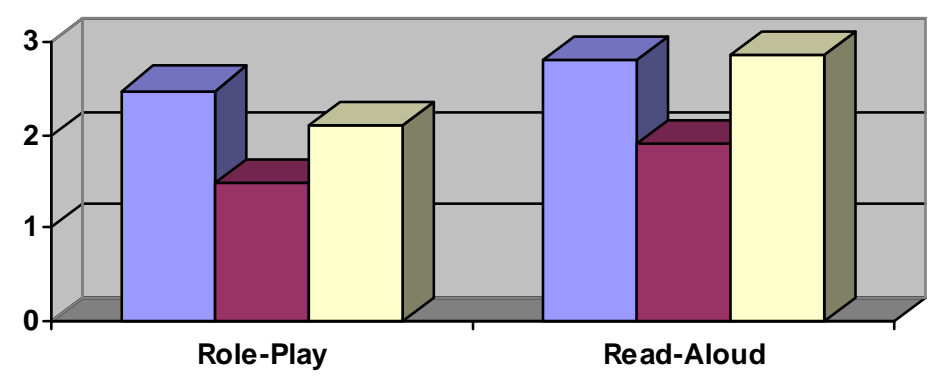

\subsubsection{Role-Play Task}

A Multivariate Analysis of Covariance (MANCOVA) was used to examine specific types of thoughts during the role-play task. The overall model was significant 
$[F(1,62)=112.00, p<.01]$. Bonferroni-adjusted pairwise comparisons revealed that socially-phobic adolescents reported more neutral thoughts related to their performance than control adolescents. The IMAG adolescents did not differ from either group on this measure of cognition. In terms of neutral task thoughts, the control group differed from both socially-phobic and IMAG adolescents, reporting a greater number of neutral thoughts related to the task. The socially-phobic and IMAG adolescents did not differ on this measure of cognition. Specific means and standard deviations for cognitions reported during the role-play task can be found in table 6 .

Table 6. Mean scores and standard deviations for Role-play Cognitions

\begin{tabular}{|l|c|c|c|}
\hline & $\begin{array}{c}\text { Social Phobia } \\
\text { Role-Play Task }\end{array}$ & $\begin{array}{c}\text { Self-Imagery } \\
(\mathrm{SD})\end{array}$ & $\begin{array}{c}\text { Control } \\
(\mathrm{SD})\end{array}$ \\
\hline Negative Performance & $(\%)$ & $(\%)$ & $(\%)$ \\
& $.29(.56)$ & $.05(.22)$ & $.10(.30)$ \\
\hline Neutral Performance & $(34)$ & $(5)$ & $(10)$ \\
& $.71(.96)$ & $.38(.50)$ & $.14(.36)$ \\
& $(43)$ & $(38)$ & $(14)$ \\
\hline Positive Performance & $.00(.0)$ & $10(.30)$ & $.05(.21)$ \\
& $(0)$ & $(10)$ & $(5)$ \\
\hline Negative Task & $.48(1.1)$ & $.10(.30)$ & $.14(.48)$ \\
& $(19)$ & $(10)$ & $(10)$ \\
\hline Neutral Task & $.76(.77)$ & $.48(.60)$ & $1.57(1.1)$ \\
& $(57)$ & $(43)$ & $(81)$ \\
\hline Positive Task & $.14(.48)$ & $.05(.22)$ & $.00(.0)$ \\
& $(10)$ & $(5)$ & $(0)$ \\
\hline Other & $.00(.0)$ & $.05(.22)$ & $.00(.0)$ \\
& $(0)$ & $(5)$ & $(0)$ \\
\hline
\end{tabular}

(\% of adolescents within group reporting at least 1 thought in respective category)

\subsubsection{Read-Aloud Task}

A MANOVA was used to examine types of thoughts reported during the readaloud task. Multivariate tests did not reveal a significant main effect for group $[F(1$, $62)=1.38, p=.21]$. Thus, further examination of cognition during the read-aloud task 
was not conducted. Specific means and standard deviations for cognitions reported during the read-aloud task can be found in table 7 .

Table 7. Mean scores and standard deviations for Read-aloud Cognitions

\begin{tabular}{|l|c|c|c|}
\hline & Social Phobia & Self-Imagery & Control \\
Read-Aloud Task & $M(\mathrm{SD})$ & $M(\mathrm{SD})$ & $M(\mathrm{SD})$ \\
& $(\%)$ & $(\%)$ & $(\%)$ \\
\hline Negative Performance & $1.0(.90)$ & $.71(1.0)$ & $.76(1.1)$ \\
& $(71)$ & $(48)$ & $(43)$ \\
\hline Neutral Performance & $.52(.87)$ & $.14(.36)$ & $.48(.60)$ \\
& $(33)$ & $(14)$ & $(43)$ \\
\hline Positive Performance & $.05(.22)$ & $.00(.0)$ & $.05(.22)$ \\
& $(5)$ & $(0)$ & $(5)$ \\
\hline Negative Task & $.48(.81)$ & $.14(.36)$ & $.48(.75)$ \\
& $(33)$ & $(14)$ & $(33)$ \\
\hline Neutral Task & $.29(.56)$ & $.52(.75)$ & $.67(.91)$ \\
& $(24)$ & $(43)$ & $(38)$ \\
\hline Positive Task & $.10(.44)$ & $.10(.30)$ & $.00(.0)$ \\
& $(5)$ & $(10)$ & $(0)$ \\
\hline Other & $.25(.72)$ & $.10(.44)$ & $.05(.22)$ \\
& $(5)$ & $(5)$ & $(15)$ \\
\hline
\end{tabular}

(\% of adolescents within group reporting at least 1 thought in respective category)

\subsection{Secondary Analyses}

\subsubsection{Changes in Anxiety}

In order to further examine the specific impact of negative self imagery on social anxiety, IMAG adolescents also were asked to rate their anxiety following the positive self-imagery role-play task. These anxiety ratings where compared to ratings of anxiety made by IMAG adolescents following the first (negative) self-imagery role-play using a repeated measure ANOVA. As depicted in figure 3, there was no significant main effect for self-imagery task $[F(1,20)=2.40, p=.137]$, indicating that IMAG adolescents rated their anxiety similarly during both the negative self-imagery $(\mathrm{M}=1.86, \mathrm{SD}=.85)$ and the positive self-imagery $(\mathrm{M}=1.57, \mathrm{SD}=.87)$ tasks. 
Figure 3. Change in anxiety for Self-imagery Role-plays

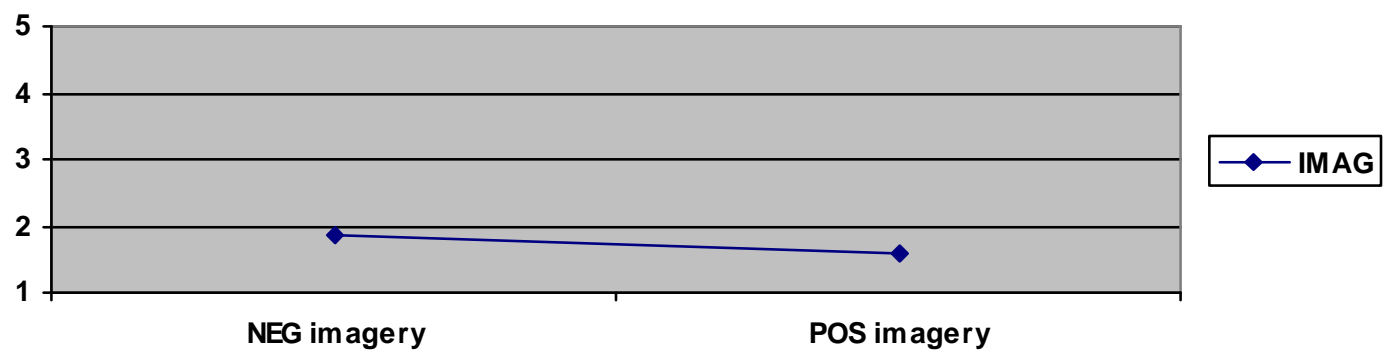

\subsubsection{Correlational Analyses}

In order to further investigate specific factors associated with anxiety and performance ratings during both behavioral tasks, bivariate correlations were computed for adolescents in the IMAG group only. For the role-play task, results revealed a large and significant correlation between total SPAI-C score and anxiety $(r=.65, p<.001)$. Total SPAIC score also was significantly negatively correlated with self-rated performance on the role-play task $(r=-.44, p<.05)$. None of the other variables were significantly associated with anxiety or self-rated performance during the role-play task, including self-imagery integrity ratings or observer rated anxiety/performance. See table 8 for correlation matrix.

Table 8. Correlations for the Role-play task among IMAG adolescents $(n=21)$

\begin{tabular}{|l|c|c|c|c|c|c|c|}
\hline Variable & SPAIC & RPanx & RPinteg & RPexp & RPperf & OBSanx & OBSperf \\
\hline SPAIC & --- & $.65^{* *}$ & -.05 & -.41 & $-.44^{*}$ & .18 & .20 \\
\hline Rpanx & & --- & -.12 & -.25 & -.37 & -.20 & -.08 \\
\hline Rpinteg & & & --- & .20 & .16 & .37 & .17 \\
\hline Rpexp & & & & --- & $.90^{* *}$ & -.22 & -.04 \\
\hline Rpperf & & & & & --- & -.13 & -.12 \\
\hline OBSanx & & & & & & --- & -.13 \\
\hline OBSperf & & & & & & & -- \\
\hline
\end{tabular}

Key: SPAIC=total SPAIC score; $\mathrm{RP}=$ role-play task; anx=self-rated anxiety; integ=self-imagery integrity rating; $\mathrm{exp}=$ self-rated expectation; $\mathrm{perf}=$ self-rated performance; $\mathrm{OBSanx}=$ observer-rated anxiety; OBSperf $=$ observer $=$ rated performance. ${ }^{*}=p<.05 ; * * p<.01$ 
For the read-aloud task, total SPAIC score was not significantly associated with anxiety or self-rated performance. However, expectation of performance on the read-aloud task was significantly negatively correlated with observer-rated anxiety $(r=.49, p<.05)$. None of the other variables were significantly associated with anxiety or self-rated performance during the read-aloud task. See table 9 for correlation matrix.

Table 8. Correlations for the Read-aloud task among IMAG adolescents $(n=21)$

\begin{tabular}{|l|c|c|c|c|c|c|c|}
\hline Variable & SPAIC & RDanx & RDinteg & RDexp & RDperf & OBSanx & OBSperf \\
\hline SPAIC & --- & .30 & .14 & -.23 & -.06 & .31 & -.07 \\
\hline Rdanx & & --- & -.01 & -.02 & -.31 & -.23 & -.29 \\
\hline Rdinteg & & & --- & .02 & .20 & .19 & -.25 \\
\hline Rdexp & & & & --- & $.73^{* *}$ & $-.49^{*}$ & .18 \\
\hline Rdperf & & & & & --- & -.18 & .39 \\
\hline OBSanx & & & & & & --- & -.06 \\
\hline OBSperf & & & & & & & -- \\
\hline
\end{tabular}

Key: SPAIC=total SPAIC score; $\mathrm{RD}=$ read-aloud task; anx=self-rated anxiety; integ=self-imagery integrity rating; $\mathrm{exp}=$ self-rated expectation; perf $=$ self-rated performance; $\mathrm{OBSanx}=$ observer-rated anxiety; OBSperf $=$ observer $=$ rated performance. ${ }^{*}=p<.05 ; * *=p<.01$ 


\section{Chapter 7: Discussion}

Recent interest in the cognitive aspects of social phobia has undoubtedly been fueled by Clark and Wells' (1995) cognitive model of the disorder. In particular, the model proposes that upon entering a feared social situation, socially-phobic individuals are excessively self-focused and flooded with negative images of themselves and their performance. It is purported that these images, in particular, directly lead to increased levels of anxiety by leading the individual to assume that others are viewing them in the same (negative) light. Although the presence of negative self-imagery among socially-phobic adults has been reported by several investigators, a majority of this research has relied upon retrospective report. Meanwhile, other investigators have reported significant bias associated with the retrospective report of self-imagery among social phobics (Coles, Turk \& Heimberg, 2002), suggesting that delayed-recall of self-imagery does not necessarily correspond with in-situation imagery. Research examining self-imagery among socially-phobic adults has typically been wrought with other limitations as well, including a lack of experimental control and the use of clinical adult samples only. Overall, based on these limitations, there exists a poor understanding of the role of negative selfimagery in the development of social phobia.

Results from this study indicate that the experience of negative self-imagery results in marginally-significant increases in anxiety during both social interactions and performance-based tasks. In addition, IMAG adolescents reported marginallysignificant decreases in their self-rated performance following the social interaction 
task compared to control subjects, while socially-phobic youth reported the lowest performance ratings across the three groups. Further, the experience of negative selfimagery during a social interaction produced significant differences in terms of overall rates of cognition. Compared to both socially-phobic and control adolescents, IMAG adolescents reported fewer cognitions during the role-play task. This difference in on-line thoughts was most evident in terms of a decrease in neutral ontask thoughts. Finally, according to blind observers, IMAG adolescents and control adolescents were rated similarly in terms of anxiety, overall effectiveness of performance and specific social skills during the behavioral tasks, while sociallyphobic youth were judged to perform worse across all domains of performance.

Because increases in self-reported anxiety and decreases in self-rated performance among IMAG adolescents during the social interaction task failed to reach statistical significance, results do not clearly indicate negative self-imagery to play a causal role in social phobia. Although it is possible that a larger sample of adolescents may have yielded significant differences between the three groups in terms of anxiety and performance, overall results from this investigation do not support this hypothesis. For example, it is noteworthy that blind observers rated the performance of the IMAG adolescents to be highly consistent with that of control adolescents. That is, although manipulation of negative cognitive-bias among the IMAG adolescents produced somewhat lower self-perceptions of performance, identifiable negative changes in behavior were not observed. Conversely, significant decreases in self-perceived performance among socially-phobic youth were in fact corroborated by blind raters during both behavioral tasks. Further, for the role-play 
task, correlational analyses revealed a significant association between total SPAI-C scores and anxiety, as well as a significant negative association between SPAI-C scores and self-rated performance among the IMAG adolescents. Thus, for the current study, existing levels of social anxiety were the strongest predictors of anxiety and self-rated performance during the social interaction task. No other variables, including self-imagery integrity ratings, were significantly associated with anxiety during either task, indicating that strength of self-imagery was not related to self-rated anxiety or performance for either task. Finally, and perhaps most surprisingly, manipulation of positive self-imagery during a second social interaction task did not produce a significant decrease in anxiety among IMAG adolescents. Rather, levels of anxiety were consistent regardless of the valence of the manipulated self-image being used. This is particularly surprising considering a potential decrease in anxiety based solely on a simple order effect for the second (positive imagery) role-play task.

In attempting to reconcile these somewhat surprising findings, the role of increased self-focused attention may be a salient one. To date, substantial literature has revealed increases in self-focused attention to produce concomitant increases in self-consciousness and anxiety among both anxious and non-anxious populations during social interactions (see Spurr \& Stopa, 2002 for an in-depth review). Selffocused attention itself represents an important aspect of Clark and Wells' (1995) model, purported to play a primary role in maintaining social phobia over time by disallowing access to other situation-specific information based on a general decrease in cognitive resources. Because the current study sought to manipulate specific types of self-imagery, unfortunately it is not possible to fully separate the potential impact 
of focusing on a specific negative self-image from that of a basic self-focus. Nonetheless, similarly elevated levels of anxiety among IMAG adolescents during both the negative and positive self-imagery tasks suggest that focusing on oneself during social situations, regardless of the specific valence of self-imagery, may have a negative impact on anxiety. From a developmental perspective, it is noteworthy that, in general, adolescence represents a period of inherent increases in self-consciousness and awareness of others' evaluations. For example, Westenberg and colleagues (2004) recently reported general increases in social-evaluative fears during adolescence and suggest such changes to be a likely corollary of socio-cognitive maturation. Accordingly, it appears that adolescents, in particular, may be highly susceptible to the effects of a manipulated self-focus, regardless of its valence. Although it is not entirely clear how well the current results might generalize to child or adult samples of social phobics, one aim of the current study was to examine the role of negative self-imagery during the period when onset of social phobia is most likely. These results suggest that excessive self-focused attention within social contexts, together with normative developmental increases in social-evaluative fears may pose a specific risk for development of social phobia during the adolescent years.

Although IMAG adolescents did not differ from control adolescents in terms of their expected performance on either task, these adolescents did endorse marginally-significant decreases in actual self-rated performance for the role-play task. It is important to note however, that follow-up univariate analyses revealed this difference to be primarily based on the fact that IMAG adolescents believed they were significantly less able to hide their anxiety from their peer during the task than 
control adolescents. This finding is consistent with reports of developmentally appropriate increases in social evaluation fears and self-consciousness during adolescence. It also should be noted that, unlike socially-phobic youth, the IMAG adolescents did not report a decreased expectation or actual self-reported ability to "think of things to say" to their peer during the social interaction, despite their increased levels of anxiety. These expectation and performance ratings were later confirmed by blind observers for both groups of adolescents. Thus, it appears that the presence of negative-self images neither impacted the IMAG adolescents' belief in their ability to generate conversation during the interaction task nor their actual ability to do so. Based on these findings, it is suggested that decreased ratings of expectation and performance among socially-phobic youth may actually reflect realistic perceptions of social skill rather than the content of in-situation negative self-images as proposed by Clark and Wells' model. Expectation of performance, in particular, may be shaped by an accumulation of negative social experiences, resulting in preemptive negative expectations thatlikely assist in maintaining anxious symptoms over time. This hypothesis is consistent with data from previous research linking continued social avoidance among children with social phobia to deficits in social skill (Beidel, Turner \& Morris, 1999; Ginsburg, LaGreca \& Silverman, 1998; Spence, Donovan \& Brechman-Toussaint, 1999).

The manipulation of negative self-imagery in the current study also impacted cognition. Specifically, IMAG adolescents reported significantly fewer thoughts than both control and socially-phobic youth during the social interaction task. This result just failed to reach statistical significance for the read-aloud task. As noted above, 
differences in cognition during the role-play task were most evident in terms of general on-task thoughts, as IMAG adolescents reported the fewest number of neutral task thoughts. The report of such thoughts generally indicated that the adolescent was focused on the actual task and usually consisted of self-statements such as "I remember when something like that happened to me" or "I play basketball too". The reduced frequency of overall cognition, and specifically on-task thoughts, reported by IMAG adolescents likely reflects the fact that the manipulation of self-imagery interfered with overall cognitive ability during the social interaction by directing a finite amount of cognitive resources toward the use of self-imagery. This reduction in cognitive resources also may have indirectly resulted in decreased ratings of performance and elevated levels of anxiety among IMAG adolescents based on a general inability to attend to the social interaction itself. Nonetheless, based on Clark and Wells' model, putative negative self-imagery among socially phobic youth should have produced similar (decreased) rates of cognition as found among the IMAG group. However, socially-phobic adolescents reported similar rates of cognition as compared to control subjects during both tasks, suggesting a general absence of competing self-imagery among anxious youth.

It is noteworthy that results from the current investigation differ somewhat from results reported by Hirsch et al. (2003), where manipulated negative selfimagery was reported to play a causal role in both significant increases in anxiety and observer-rated decreases in performance among socially-phobic adults. One obvious explanation for these different sets of findings includes the fact that Hirsch and colleagues manipulated self-imagery among a sample of socially-phobic adults who 
may have been more susceptible to the effects of negative self-images (both in terms of anxiety and performance) based both on the duration and severity of their psychopathology. Also, the use of adult subjects who already suffer from the disorder does not permit a temporal understanding of the factors involved in the onset of social anxiety. In contrast, the current study sought to address these limitations by examining the potential impact of negative self-imagery among a group of nonanxious adolescents. Along these lines, it is important to note that both groups of nonanxious adolescents included in the current study represented adolescents with a normative range of non-clinical social fears, as evidenced by their scores on the SPAI-C. Thus, it is unlikely that the current results can be explained based on a selection bias of overly-extraverted and/or socially-skilled youth. It also should be noted that negative self-imagery selected for use in the current study reflected the content of images reported by adult social-phobics in previous studies (Hackmann et al., 1998; Hackmann et al., 2000). Specifically, in order to ensure emotional salience, adolescents in the self-imagery group were asked to focus on a recent real-life situation in which they were embarrassed, messed up, felt foolish, or made a mistake in front of others. Although it is not clear whether focusing on a hypothetical negative social situation might produce dissimilar results, it is the personal meaning of negative self-imagery (i.e., not imagery itself) that is purported to be salient in maintaining social phobia over time (see Hirsch et al., 2003).

In addition to the study by Hirsch and colleagues, numerous other studies have reported the presence of negative self-images among socially-phobic individuals during social situations. Unfortunately, most of these studies have relied on 
retrospective report in establishing the presence of self-imagery. Although it is possible that socially-phobic individuals re-experience negative social memories in the form of vivid self-imagery, currently, there is little evidence indicating that they are actually experienced during social situations as opposed to when one is later asked to recall these events. For example, Coles, Turk and Heimberg (2002) examined self-imagery among socially-phobic and non-anxious adults both immediately following two social interaction tasks and at a 3-week follow-up period. Results indicated significant differences in the content and intensity of self-imagery reported immediately after the tasks and at the 3-week follow-up period, lending support to concerns raised regarding the use of retrospective report and indicating that post-hoc appraisals of imagery do not necessarily correspond with in-situation experiences. Nonetheless, even if some amount of negative self-imagery is present within actual social settings, results reported here suggest that these cognitive events may simply act as amplifiers of pre-existing levels of social anxiety, rather than causal factors in the development of social phobia.

Another important distinction between the current findings and those reported by Hirsch and colleagues involves the role of social skills. Disentangling actual social skill deficits from situation-specific nervous behaviors (referred to by Clark and Wells as "safety-behaviors") among children with social anxiety has been the focus of recent attention and represents an important area of research. Results from one recent study suggest that commonly observed deficits in social skill among socially-anxious youth may not in fact require remediation through social skills training programs, but rather, might be best conceptualized as a temporary result of intense physiological 
arousal (Cartwright-Hatton, Hodges \& Porter, 2003). The current results do not support this assertion. Although IMAG adolescents did report non-significant increases in anxiety during both behavioral tasks, blind observers judged their performance similar to that of control adolescents. Further, separate from overall ratings of performance, blind observers were asked to rate two specific aspects of behavior representing discrete social skills: eye-contact/facial gaze and speech latencies. Socially-phobic youth were judged to exhibit less appropriate eye contact/facial gaze and required approximately three times as long to respond to their peer during the social interaction task compared to both IMAG and control adolescents. This is particularly noteworthy considering an apparent decrease in available cognitive resources among IMAG adolescents during the social interaction task. Of course, the fact that the sample used in the study by Cartwright-Hatton and colleagues (2003) included younger children who were highly socially-anxious (versus clinically-anxious) may serve to explain some differences in these two sets of findings. In the current study however, it does not appear that temporary increases in physiological arousal are sufficient to explain observable deficits in social skill among socially-phobic youth.

As in all studies, several limitations should be considered. First, the possibility that demand characteristics may have been present during the behavioral assessment cannot fully be ruled-out. Although adolescents were provided with specific instructions prior to the tasks, and in particular, were instructed to act as they would in a real-life social situation, the possibility remains that the self-report of IMAG adolescents may have been somewhat influenced by the nature and description of the 
task. Additionally, although measures were taken to ensure the emotional salience of manipulated self-imagery, the degree to which self-images used in the current study correspond with putative self-imagery experienced by socially-phobic individuals is not entirely clear. For example, it may be the case that overall intensity of selfimagery, as compared to the actual content, is most salient in impacting anxiety. This possibility awaits further study. Also, although most adolescents completed the behavioral tasks with a gender-matched peer, a few subjects across each of the three groups completed the tasks with a peer of the opposite sex (when a same-sex peer was unavailable). Given the importance of romantic and dating relationships during adolescence (Glickman \& LaGreca, 2004), it is not clear how the presence of an opposite-sex peer may affect levels of anxiety during such behavioral tasks. Also, in the absence of an adult comparison group, conclusions about the development and maintenance of cognitive aberrations over time are somewhat speculative.

Longitudinal designs are needed to fully understand how cognitive phenomena, including negative self-imagery, may impact social-anxiety across different levels of development.

Despite these limitations, the current findings shed light on the role of cognitive factors in the development of social phobia and raise important questions that remain to be examined as part of future research. Most notably, although measures were taken in the current study to ensure the adequate use of negative selfimagery, as noted above, these data do not allow for the effects of manipulated selfimagery to be disentangled from the effects of simple self-focused attention. However, the current results suggest this as an area worthy of further investigation. 
Currently, there exists a poor understanding of the role of attentional focus in the development and maintenance of social phobia. For instance, although an excessive self-focus has commonly been implicated, there also is evidence to suggest that social-phobics frequently direct their attention toward threatening stimuli within their environment (Asmundson \& Stein, 1994; Hope et al., 1990). Although different proposals of attentional focus are not necessarily mutually exclusive, theoretical models have generally done a poor job of considering and incorporating these findings. Further evidence for this fact comes from findings on cognition. Specifically, although several researchers propose greater amounts of negative selfthoughts within social settings to lead to elevated levels of social anxiety, results from the current investigation suggest that a decreased ability to focus on the actual social situation, rather than the presence of negative self-thoughts, may lead to increased levels of social anxiety. Overall, a better understanding of the specific role of attentional focus in social anxiety and related performance is needed. Research based on the use of non-anxious samples will better allow for etiological factors in the development of social phobia to be partitioned from diagnostic outcomes, as this has been a major limitation of previous research. Finally, because cognitive phenomena associated with the disorder likely differ across levels of social and cognitive development, a developmental focus is needed in investigating factors associated with the occurrence and maintenance of social phobia over time. 
Appendix A

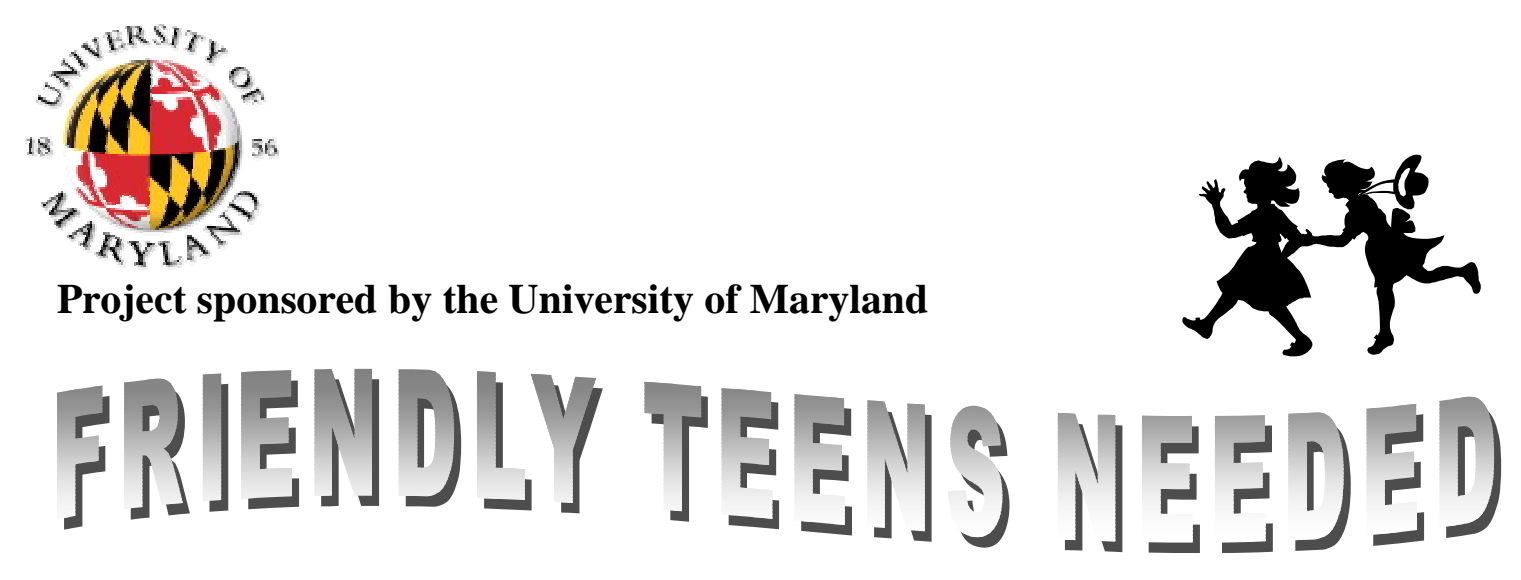

Friendly adolescents (ages 12-16) are needed to participate in a research program involving shy and not-shy adolescents. All participants will have the opportunity to participate in after school and Saturday activities such as roller skating, bowling, lazer tag, etc. All admission fees and lunches/snacks will be provided by the project. Parents are responsible for transportation to and from the activity.

For additional information please contact Candice Alfano at the Maryland Center for Anxiety Disorders, Department of Psychology, University of Maryland, College Park, (301) 405-0232.
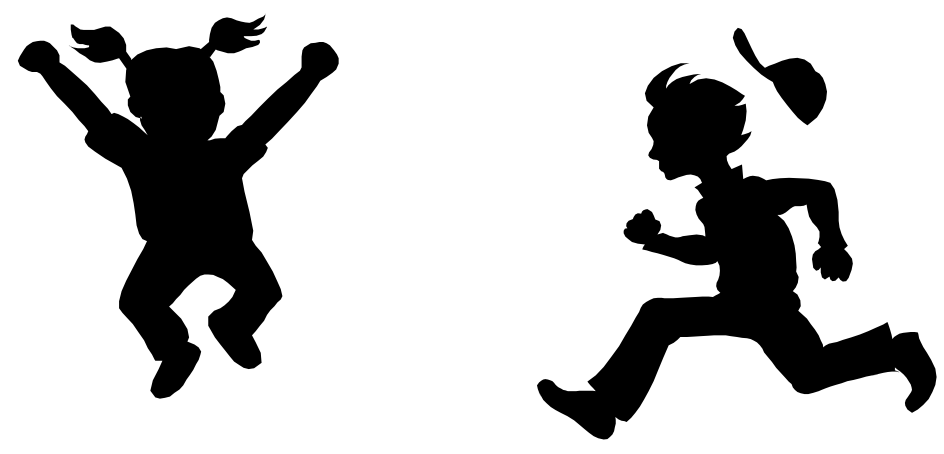


\title{
Appendix B
}

\author{
Initials: \\ Date: \\ Page 1 of 3
}

\section{Permission Form}

\section{Consent for Participation in the Cognitions Project}

\section{Project Title: Cognition in Childhood Social Phobia}

I state that I am over 18 years of age, in good physical health, and the parent/legal guardian of . I wish for my child, , who is between 12 and 16 years of age, to participate in a research study designed to help researchers better understand the role of cognition in childhood social anxiety. This program is being conducted by Dr. Deborah C. Beidel, Dr. Samuel M. Turner, and Ms. Candice Alfano, Department of Psychology, University of Maryland, College Park, MD 20742.

Purpose: There are different theories about the development of social anxiety (extreme shyness). The purpose of this study is to determine if certain types of thoughts/images may increase children's anxiety in social situations. By participating in this study my child will assist researchers in better understanding how to help children with social anxiety.

Procedures: My child and I will participate in a diagnostic screening to determine whether my child is eligible to participate in the study. This interview will last approximately 30-45 minutes. If during this screening, it is determined that my child is suffering from anxiety, depression, or behavioral problems, I will be given a referral for appropriate treatment services for my child by a member of the MCAD staff. If my child is suffering from any of the above problems, he/she will not be eligible to participate in the current study.

My child will participate in a behavioral assessment. This will require my child to interact with another child (a "peer") in a series five short "role-play" scenes that depict real-life situations. For example, my child may be asked to imagine that he or she is at school and to respond to a compliment given by another child. My child also will be asked to read aloud for 10 minutes in front of the peer. These assessments will be videotaped. My child's behaviors will be compared to the behaviors of shy children. Before and after both behavioral tasks, my child will complete a short 4 -item questionnaire regarding his/her expectations and actual performance on these tasks. Also, immediately following the role-play and the read-aloud tasks, my child will be asked to view a videotape of the tasks he/she just performed and will be asked to retrospectively recall his/her thoughts during the tasks. This assessment will take approximately 30 minutes. 
Initials:

Date:

Page 2 of 3

One purpose of this study is to determine if thinking certain thoughts can make children feel nervous during social situations. So my child may be asked to think about the types of thoughts shy children report that they have when they are with another child. For example, my child may be asked to imagine saying the wrong thing, messing up, or performing poorly. If my child is asked to think about these thoughts, he/she will then be asked to think positive thoughts (performing well, saying the perfect thing, or looking "cool" in front of peers) when the task is over.

Compensation: My child will be paid $\$ 15$ as compensation for his/her time and effort.

Confidentiality: All information collected in the study will be kept confidential to the fullest extent of the law. Research records, like hospital records, may be subject to subpoena or court order. My name, or that of my child will not be in the data files. All materials are coded only by a subject number. The videotapes, like all other materials in this project, are confidential and are only available to project staff. Videotapes are erased after they are scored by the research staff. All information is kept in locked files in the investigators offices. The data that my child and I provide will be grouped with data others provide for reporting and presentation.

Risks: I understand that my child may feel some very mild nervousness when first participating in the assessments, but because my child is not shy, this will not be more than he/she would probably feel if reading aloud/talking to another child at school. I also understand that my child may feel some nervousness if he/she is asked to think "anxious" thoughts during the behavioral assessment. However, because my child is not socially-anxious or depressed and because previous research using anxious-imagery techniques has indicated this to be a safe exercise, any lasting effects are unlikely. Additionally, if my child is asked to think anxious thoughts, he/she will repeat the task but be given positive thoughts to imagine instead. This final task is designed to minimize or eliminate any temporary nervousness.

I understand that my child's participation is voluntary and therefore we are free to ask questions or withdraw from the study at any time.

Benefits: My child may take pleasure in helping researchers develop effective treatments for children with social fears. I understand that this study will not benefit my child personally. 
Initials:

Date:

Page 3 of 3

If you have questions about your child's rights as a research subject or wish to report a research-related injury, please contact: Institutional Review Board Office, University of Maryland, College Park, Maryland, 20742; (e-mail) irb@deans.umd.edu; (telephone) 301-405-4212

Deborah C. Beidel, Ph.D. $\quad$ Printed Name of Child:

Professor of Psychology Printed Name of Parent:

Department of Psychology

University of Maryland

College Park, MD 20742

(301) 405-0232

Parent Signature:

Witness:

Date: 


\section{Informed Assent Form}

\section{Participation in the Cognitions Project}

Project Title: Cognition in Childhood Social Phobia

I am between the ages of 12 and 16 years of age and I agree to be in a study with Dr. Deborah C. Beidel, Dr. Samuel M. Turner and Ms. Candice Alfano at the Department of Psychology, University of Maryland, College Park, MD 20742.

Purpose: The doctors are trying to find out if thinking certain types of thoughts make shy children feel nervous, but first they want to find out if these thoughts make children who are not shy feel nervous. This information will allow the doctors to help shy children feel less nervous in social situations.

Procedures: First, my mom or dad and I will be interviewed about any fears that I have and about times when I feel nervous or sad. Then, I will be participating in a behavioral assessment. This means that I will interact with another adolescent who is my age in 5 "role-play" scenes (a role-play is like a short skit) and by reading out loud for 10 minutes. Afterwards, I will rate how nervous I was and answer some other questions about my performance on the tasks. After we do the role-plays and I read out loud, I will watch a videotape of the same two tasks and I will try to remember what I was thinking during the tasks.

Also, since the doctors are interested in finding out how certain types of thoughts make children act and feel, they may ask me to imagine some things during the behavioral assessment. I can ask questions or discontinue any of the tasks at any time during the assessment.

Compensation: I will receive $\$ 15.00$ for my time and effort.

Confidentiality: Information about me will be kept secret and my name will not be used.

Risks: I may feel nervous during the assessment, but not more than if I were reading out loud in the classroom or talking to another child at school. Also, I may feel nervous if I decide to participate in the imagery tasks. However, since these images will only be pretend images, any nervousness I may feel will probably not last for long. Also, if I do feel nervous I can stop any of the tasks at any time and I should tell Drs. Beidel and Turner and/or Ms. Alfano how I feel.

Benefits: I will be helping the doctors to find ways to help shy children feel less nervous in social settings.

Deborah C. Beidel, Ph.D. Printed Name of Child: Department of Psychology Child Signature:

University of Maryland

College Park, MD 20742 Date:

(301) 405-0232

Witness: 


\section{Appendix C}

\section{Dialogue for Behavioral Assessment}

Peer Instructions: When the peer enters the room (before the subject is present) explain the procedure for the behavioral assessment, including the following:

1) Give the participant at least 10 seconds to respond to each role-play statement.

2) Maintain eye-contact with the participant during the role-plays.

3) The participant's anxiety ratings are confidential.

4) The participant's expectation and performance ratings are confidential.

Participant Instructions: When the participant comes into the room introduce him/her to the peer and provide the following explanation for the behavioral assessment:

"We are going to do 2 different things today: a role-play task and a read-aloud task, which I will describe in detail shortly. After each task I am going to ask you to use this sheet (SAM rating) to describe how nervous you felt during each task. (Explain SAM ratings from $1=$ not nervous to 5=very nervous) Also, before we begin each task I will ask you to answer 4 questions about how well you expect to perform on each task. (Explain expectancy ratings from 1= poorly to 4=well) After each task I will ask you to answer 4 similar questions using the same 4 point scale, but these questions will be about how well you think you actually performed on each task. There are no right or wrong answers to these questions. Do you have any questions about the different ratings?"

\section{Role-Play:}

"A role-play is kind of like a short skit. I am going to describe 5 situations and [Peer's Name] is going to say some things to you that another child/adolescent your age might say in real-life. I would like you to respond to [Peer's Namel just as you would in real-life, and if you wouldn't say anything that's fine too. We will do a practice scene first and if you have any questions you can ask me at that time. Also, you may discontinue the task at any time you wish during the role-play scenes."

\section{$\underline{\text { Read-Aloud Task: }}$}

"Now I would like you to pick up [The Ransom of Red Chief] and read aloud for 10 minutes. I will tell you when to stop reading. If you wish, you may discontinue the read-aloud task at any time. Do you have any questions?" 


\section{Dialogue for Self-Imagery task}

Participant Instructions: Prior to entering the assessment room with the participant provide the adolescent with the following explanation for the self-imagery task:

"We are going to do 3 different things today: a role-play task, a read-aloud task, and a second rolep lay task, all with another adolescent your age. I will describe all of these tasks in detail shortly, but first I want to explain to you what self-imagery is. Self-imagery is when you hold a very specific picture of yourself in your mind and you imagine that image really happening in real-life. Some examples of selfimagery include imagining yourself scoring the winning touchdown, imagining yourself giving a presentation, or imagining yourself graduating from high school. [Ask adolescent for another example of self-imagery]. Because we are interested in finding out how different kinds of self-imagery may affect people's behavior, I am going to ask you to use 2 different kinds of self-imagery today during the role-play and read aloud tasks.....”

"During the first two tasks ( $1{ }^{\text {st }}$ role-play and read-aloud) I would like for you to imagine yourself doing something negative. For example, you might imagine yourself messing up, saying the wrong thing, or looking silly in front of your peer. We call this negative self-imagery. In order to help you use negative self-imagery during the $1^{\text {st }}$ two tasks, I want you to think of a time in the past when you messed up or did something incorrectly in front of others. Try to think of a time when you felt really embarrassed. This might have happened at school, at a friend's house or at camp. Can you think of such a time? [Ask adolescent to explain situation in detail while closing their eyes. If adolescent appears to have difficulty coming up with a specific time, use further prompting (e.g., How about at a party, on vacation, at the mall, or during class? Did you ever trip/fall down in front of others, give the wrong answer in class, or drop a bunch of books? If adolescent cannot think of a time after further prompting, assist them in using "pretend" negative self-imagery for the tasks (e.g., getting their words all mixed up, saying the wrong word, having their hands shake). Ensure understanding of self-imagery before continuing with the assessment].

"During the third and final task ( $2^{\text {nd }}$ role-play), I would like for you to use a different kind of self-imagery, called positive self imagery. What do you think positive self-imagery is? That's right! Positive self-imagery would be imagining yourself performing really well, looking really cool, or getting all the answers correct. So during the third task, I would like for you to think of a time when you felt really good about how you performed in front of others. This might have happened at school, at a party or at camp. Can you think of such a time? [Use same procedure as above to ensure understanding and use of self-imagery] 
"For the first two tasks I will be using a red light to remind you to begin, continue and discontinue using the negative self-image you chose. So, when I turn the red light on that is your cue to start using the negative self-image. Remember, you should continue using the same negative self-imagery until the light goes off. For the third and final task I will use a blue light to remind you to begin, continue and discontinue using the positive self-image you chose. Again, you should continue using the same positive self-image until the light goes off. During all of these tasks, your peer will not know that you are using any self-imagery, only you and I will know. Finally, you may stop any of the tasks at any point during the assessment. Do you have any questions about any part of the behavioral tasks?" [Ensure the adolescent's complete understanding of the task before continuing with assessment] 
Following the role-play and read-aloud tasks and after the peer leaves the room, the following should be explained to the subject:

"Ok now we are going to do something different. I am going to show you a videotape of the tasks you just performed. As you watch the tape, I want you to try to remember exactly what you were thinking while you were performing the tasks. I am going to stop the tape four times, twice during each task, and when I stop the tape I am going to ask you to tell me exactly what you were thinking at that very moment. So, I do not want you to tell me what you are thinking right now. Instead, I want to know what you were thinking during the actual tasks. If you were not thinking anything during tasks, that is $O K$. Do you have any questions about the recall task? (Ensure subject's understanding of the task prior to proceeding).

For each of the four times the tape is stopped, ask the subject the following:

First prompt: "Now tell me everything you were thinking at that moment?

Write the subject's thoughts on the video-mediated recall sheet verbatim. If the subject reports at least one thought use the second prompt.

Second prompt: “What else were you thinking at that moment? 


\section{Appendix D}

Self-Imagery Integrity

ID\#

Date

\section{Circle your answers.}

1) During the first role-play task, you imagined yourself

How well were you able to hold this image in mind during the first role-play task?

1

not at all/

a little bit
2

some of the time
3

a lot of the time
4

most/all the time

2) During the read-aloud task, you imagined yourself

How well were you able to hold this image in mind during the read-aloud task?

$\begin{array}{cccc}1 & 2 & 3 & 4 \\ \text { not at all } / & \begin{array}{c}\text { some of the } \\ \text { time }\end{array} & \begin{array}{c}\text { a lot of the } \\ \text { time }\end{array} & \text { most/all the time } \\ \text { a little bit } & & \end{array}$

3) During the second role-play task, you imagined yourself

How well were you able to hold this image in mind during the second role-play task?

1

not at all/

a little bit
2

some of the

time

3
a lot of the
time

time
4

most/all the time 
ID\#

Date

\section{Circle your answers.}

Please use the 4-point scale below each question to rate how well you think you will perform on the read-aloud task.

\section{$1=$ poorly 2 =somewhat poorly 3 =somewhat well $4=$ well}

\section{Compared to other kids your age......}

1)......how well do you think you will be able to read aloud?

$\begin{array}{llll}1 & 2 & 3 & 4\end{array}$

2)......how well do you think you will be able to hide how scared you are while reading aloud?
1
2
3
4

3)......how well do you think you will be able to pronounce the difficult words?

$\begin{array}{lllll}1 & 2 & 3 & 4\end{array}$

4)......how well do you think your peer thinks you will do on the read-aloud task?

1

2

3

4 
ID\#

Date

\section{Circle your answers.}

Please use the 4-point scale below each question to rate how well you think you actually performed on the read-aloud task.

\section{$1=$ poorly 2 =somewhat poorly 3 =somewhat well $4=$ well}

\section{Compared to other kids your age......}

1)......how well do you think you were able to read aloud?

$\begin{array}{llll}1 & 2 & 3 & 4\end{array}$

2)......how well do you think you were able to hide how scared you are while reading aloud?
1
2
3
4

3)......how well do you think you were able to pronounce the difficult words?

$\begin{array}{llll}1 & 2 & 3 & 4\end{array}$

4)......how well do you think your peer thought you did on the read-aloud task?

1

2

3

4 


\section{Role-Play Expectation}

ID\#

Date

Circle your answers.

Please use the 4-point scale below each question to rate how well you think you will perform on the role-play task.

\section{$1=$ poorly $2=$ somewhat poorly $3=$ somewhat well $\quad 4=$ well}

\section{Compared to other kids your age......}

1)......how well do you think you will perform on the role-plays?

$\begin{array}{llll}1 & 2 & 3 & 4\end{array}$

2)......how well do you think you will be able to hide how scared you are during the role-plays?

$\begin{array}{llll}1 & 2 & 3 & 4\end{array}$

3)......how well do you think you will be able to think of things to say to your peer during the role-plays?
1
2
3
4

4)......how well do you think your peer thinks you will do on the role-plays? 
ID\#

Date

\section{Circle your answers.}

Please use the 4-point scale below each question to rate how well you think you actually performed on the role-play task.

\section{$1=$ poorly $2=$ somewhat poorly $3=$ somewhat well $\quad 4=$ =well}

\section{Compared to other kids your age......}

1)......how well do you think you performed on the role-plays?

$\begin{array}{llll}1 & 2 & 3 & 4\end{array}$

2)......how well do you think you were able to hide how scared you were during the role-plays?

$\begin{array}{llll}1 & 2 & 3 & 4\end{array}$

3)......how well do you think you were able to think of things to say to your peer during the role-plays?
1
2
3
4

4)......how well do you think your peer thought you did on the role-plays?

$\begin{array}{llll}1 & 2 & 3 & 4\end{array}$




\section{Appendix E}

Observer Ratings

Patient ID\#:

Assessment \#:

Tape \#:

Rater Name:

Rater \#: 1 or 2

Date:

\section{Social Skills \\ Rating of Latency}

Record the number of seconds between when the child actor finishes each line and when the shy child begins to speak (0-10 seconds).

Scene $1 \quad$ Line $1 \_$Line 2

Scene 2 Line 1 Line 2

Scene $3 \quad$ Line $1 \ldots$ Line 2

Scene $4 \quad$ Line $1 \ldots$ Line 2

Scene 5 Line 1 Line 2

Average time of all scenes

\section{Rating of Facial Gaze}

YES = Maintained appropriate eye contact while speaking

$\mathrm{NO}=$ Did not maintain appropriate eye contact while speaking

Scene 1

Yes

No

Scene 2

Yes

No

Scene 3

Yes

No

Scene 4

Yes

No

Scene 5

Yes

No

Average 


\section{OBSERVER RATING \\ SOCIAL SKILLS \\ RATING OF ANXIETY}

$1 \quad$ Not at all anxious: No overt signs of anxiety, smiles at conversational partner, appears interested and/or enjoys the interaction.

$2 \quad$ Mildly anxious: Occasional signs of anxiety, which consist primarily of facial apprehension (furrowed brow, eyes wide open), or awkward body movement (slight hand wringing, awkward seating position).

3 Moderately anxious: Clear signs of discomfort, awkward, some gross motor movements as above, but less extreme and/or less consistent than above.

$4 \quad$ Severely anxious: Uncomfortable, gross motor signs of anxiety exhibited consistently (hand wringing, or turning, leg shaking, fidgety). Also could be manifested as extreme inhibition ("frozen with fear")

Rate each scene separately

\begin{tabular}{lllll} 
Scene 1 & 1 & 2 & 3 & 4 \\
Scene 2 & 1 & 2 & 3 & 4 \\
Scene 3 & 1 & 2 & 3 & 4 \\
Scene 4 & 1 & 2 & 3 & 4 \\
Scene 5 & 1 & 2 & 3 & 4 \\
\hline
\end{tabular}

Score (Average of all scenes) 


\section{OBSERVER RATING \\ SOCIAL SKILLS \\ EFFECTIVENESS RATING}

$1 \quad$ Not effective at all: Looks awkward, no response or one word response, does not ask questions, mumbling, barely audible speech.

2 Minimally effective: Clearly awkward, answers questions but mainly gives two or three would responses, and no further participation in conversation, voice volume low and weak.

$3 \quad$ Moderately effective: Only mild awkwardness, able to respond to questions fully, some degree of fluidity, and moderate effort to keep conversation going, voice volume moderate.

$4 \quad$ Effective: No awkwardness, carries part of the conversation, may selfdisclose, appears to enjoy the interaction, voice strong and clear.

Rate each scene separately

\begin{tabular}{lllll} 
Scene 1 & 1 & 2 & 3 & 4 \\
Scene 2 & 1 & 2 & 3 & 4 \\
Scene 3 & 1 & 2 & 3 & 4 \\
Scene 4 & 1 & 2 & 3 & 4 \\
Scene 5 & 1 & 2 & 3 & 4 \\
\hline
\end{tabular}

Score (Average of all scenes) 


\section{OBSERVER RATING}

\section{READING ALOUD \\ ANXIETY RATING}

$1 \quad$ Not at all anxious: No overt signs of anxiety, smiles, appears interested and/or enjoys interaction.

2 Mildly anxious: Occasional signs of anxiety, which consist primarily of apprehension (furrowed brow, eyes wide open), or awkward body movement (slight hand wringing, awkward seating position).

$3 \quad$ Moderately anxious: Clear signs of discomfort, awkward, some gross motor movements as above, but less extreme and/or less consistent than above.

4 Severely anxious: Uncomfortable, gross motor signs of anxiety exhibited consistently (hand wringing, or turning, leg shaking, fidgety). Also could be manifested as extreme inhibition ("frozen with fear"). 


\section{OBSERVER RATING \\ READING ALOUD \\ EFFECTIVENESS RATING}

$1 \quad$ Not effective at all: Looks awkward, does not read or does so in a very hesitant fashion. May skip words such that meaning is lost.

2 Minimally effective: Clearly awkward, words are read one at a time rather than as a fluid sentence. Mispronounces common words, voice volume weak.

$3 \quad$ Moderately effective: Only mild awkwardness. Reads capably, only mispronouncing difficult words, voice volume acceptable.

$4 \quad$ Effective: Good presentation skill, voice volume strong, reads with appropriate inflection and expression. Appears to enjoy the presentation. 


\section{Appendix F}

$\underline{\text { Role-Play Video-mediated Recall: }}$

A) Stop the tape after the first role-play scene and ask the subject the following.....

"Now tell me everything you were thinking at that very moment." (Record all thoughts separately and verbatim)

If the subject reported at least one thought continue with the following prompt......

“What else were you thinking at that moment?"

B) Stop the tape after the second role-play scene and ask the subject the following......

"Now tell me everything you were thinking at that very moment." (Record all thoughts separately and verbatim)

If the subject reported at least one thought continue with the following prompt......

"What else were you thinking at that moment?" 
$\underline{\text { Read-Aloud Video-mediated Recall: }}$

A) Stop the tape after the first minute of the reading and ask the subject the following......

“Now tell me everything you were thinking at that very moment." (Record all thoughts separately and verbatim)

If the subject reported at least one thought continue with the following prompt......

"What else were you thinking at that moment?"

B) Stop the tape after the third minute of the reading and ask the subject the following......

"Now tell me everything you were thinking at that very moment." (Record all thoughts separately and verbatim)

If the subject reported at least one thought continue with the following prompt......

“What else were you thinking at that moment?" 


\section{Bibliography}

Albano, M. A. (2000). Treatment of social phobia in adolescents: Cognitive behavioral programs focused on intervention and prevention. Journal of Cognitive Psychotherapy, 14, 67-76.

Alden, L.E. \& Wallace, S.T. (1995). Social phobia and Social appraisal of in successful and unsuccessful social interactions. Behaviour Research and Therapy, 33, 497-505.

Alfano, C.A., Beidel, D.C., \& Turner, S.M. (2005). Cognitive correlates of social phobia among children and adolescents. Manuscript under review.

Alfano, C.A., Beidel, D.C., \& Turner, S.M. (2002). Cognition in childhood anxiety: Conceptual, developmental, and methodological issues. Clinical Psychology Review, 22, 1209-1238.

Alfano, C.A., Beidel, D.C., \& Turner, S.M. (November, 2001). Changes in cognition following a behavioral treatment for social phobia. Poster presented at the annual meeting of the Association for the Advancement of Behavior Therapy. Philadelphia, PA.

American Psychiatric Association (1994). Diagnostic and Statistical Manual of Mental Disorders, Fourth Edition. Washington, DC: American Psychiatric Association

American Psychiatric Association (1987). Diagnostic and Statistical Manual of Mental Disorders, Third Edition - Revised. Washington, DC: American Psychiatric Association 
Asmundson, G.J.G., \& Stein, M.B. (1994). Selective processing of social threat in patients with generalized social phobia: evaluation using a dot-probe paradigm. Journal of Anxiety Disorders, 8, 107-117.

Beidel, D.C. (1991). Social phobia and overanxious disorder in school-aged children. Journal of the American Academy of Child and Adolescent Psychiatry, 30, $545-552$.

Beidel, D.C., Christ, M.A.G. \& Long, P.J. (1991). Somatic Complaints in anxious children. Journal of Abnormal Child Psychology, 19, 659-670.

Beidel, D.C. \& Turner, S.M. (1998). Shy children, phobic adults: The nature and treatment of social phobia. Washington DC: American Psychological Association

Beidel, D.C., \& Turner, S.M. (1988). Comorbidity of test anxiety and other anxiety disorders in children. Journal of Abnormal Child Psychology, 16, 275-287.

Beidel, D.C., Turner, S.M. \& Dancu, C.V. (1985). Physiological, cognitive, and behavioral aspects of social anxiety. Behaviour Research and Therapy, 23, 109117.

Beidel, D.C., Turner, S.M., Hamlin, K., \& Morris, T.L. (2000). The social phobia and anxiety inventory for children (SPAI-C): External and discriminative validity. Behavior Therapy, 31, 75-87.

Beidel, D.C., Turner, S.M. \& Morris, T.L. (2000). Behavioral treatment of childhood social phobia. Journal of Consulting and Clinical Psychology, 68, 10721080. 
Beidel, D.C., Turner, S.M., \& Morris, T.L. (1999). Psychopathology of childhood social phobia. Journal of the American Academy of Child and Adolescent Psychiatry, 38, 643-650.

Beidel, D.C., Turner, S.M. \& Morris, T.L. (1995). A new inventory to assess childhood social anxiety and phobia: The Social Phobia and Anxiety Inventory for Children. Psychological Assessment, 7, 73-79.

Bruch, M.A., Giordano, S., \& Pearl, L. (1986). Differences between fearful and self-conscious shy subtypes in background and current adjustment. $\underline{\text { Journal of }}$ Research in Personality, 20, 172-186.

Brunello, N., de Boer, J. A., Judd, L. L., Kasper, S., Kelsey, J. E., Lader, M., Lecrubier, Y., Lepine, J. P., Lydiard, R. B., Mendlewicz, J., Montgomery, S. A., Racagni, G., Stein, M. B. \& Wittchen, H. U. (2000). Social phobia: Diagnosis and epidemiology, neurobiology, and pharmacology, comorbidity, and treatment. $\underline{\text { Journal }}$ of Affective Disorders, 60, 61-74.

Bogels, S.M., \& Zigterman, D. (2000). Dysfunctional cognitions in children with social phobia, separation anxiety disorder, and generalized anxiety disorder. Journal of Abnormal Child Psychology, 28, 205-211.

Cartwright-Hatton, S., Hodges, L. \& Porter, J. (2003). Social anxiety in childhood: the relationship with self and observer rated social skills. Journal of Child Psychology and Psychiatry, 44, 737-742.

Chansky, T.E. \& Kendall, P.C. (1997). Social expectancies and selfperceptions in anxiety-disordered children. Journal of Anxiety Disorders, 11, 347363. 
Clark, D.M. \& Wells, A. (1995). A cognitive model of social phobia. In R.G. Heimberg, M.R. Liebowitz, D.A. Hope \& F.R. Schneier (Eds.) Social phobia: diagnosis, assessment and treatment. Guilford Press: New York, NY.

Coles, M.E., Turk, C.L. \& Heimberg, R.G. (2002). The role of memory perspective in social phobia: immediate and delayed memories for role-played situations. Behavioral and Cognitive Psychotherapy, 30, 415-425.

Davidson, J. (1993). Childhood histories of adult social phobics. Presented at the Anxiety Disorders Association Annual Convention, Charleston, SC, March.

DeWit, D.J., Ogborne, A., Offord, D.R. \& MacDonald, K. (1999). Antecedents of the risk of recovery from DSM-III-R social phobia. Psychological Medicine, 29, 569-582.

Emmelkamp, P.M., Mersch, P.P., Vissia, E. \& Van der Helm, M. (1985). Social phobia: A comparative evaluation of cognitive and behavioral interventions. Behaviour Research and Therapy, 23, 365-369.

Foa, E.B., Franklin, M.E., Perry, K.J. \& Herbert, J.D. (1996). Cognitive biases in generalized social phobia. Journal of Abnormal Psychology, 105, 433-439.

Glickman, A.R. \& LaGreca, A.M. (2004). The dating anxiety scale for adolescents: scale development and associations with adolescent functioning. Journal of Clinical Child and Adolescent Psychology, 33, 566-578.

Ginsburg, G.S., LaGreca, A.M. \& Silverman, W.K. (1998). Social anxiety in children with anxiety disorders: relation with social and emotional functioning. Journal of Abnormal Child Psychology, 26, 175-185. 
Hackmann, A., Clark, D.M. \& McManus, F. (2000). Recurrent images and early memories in social phobia. Behaviour Research and Therapy, 38, 601-610.

Hackmann, A., Surawy, C. \& Clark, D.M. (1998). Seeing yourself through others' eyes: a study of spontaneously occurring imagery in social phobia. Behavioral and Cognitive Psychotherapy, 26, 3-12.

Heimberg, R.G., Hope, D.A., Dodge, C.S. \& Becker, R.E. (1990). DSM-III-R subtypes of social phobia: comparison of generalized social phobia and public peaking phobia. Journal of Nervous and Mental Disease, 178, 172-179.

Heimberg, R.G., Stein, M.B., \& Hiripi, E. \& Kessler, R.C. (2000). Trends in the prevalence of social phobia in the United States: a synthetic cohort analysis of changes over four decades. European Psychiatry, 15, 29-37.

Hirsch, C., Clark, D.M., Mathews, A. \& Williams, R. (2003). Self-images play a causal role in social phobia. Behaviour Research and Therapy, 41, 909-921.

Hope, D.A., Rapee, R.M., Heimberg, R.G. \& Dombeck, M.J. (1990). Representations of the self in social phobia: vulnerability to social threat. Cognitive Therapy and Research, 14, 177-189.

Hudson, J.L. \& Rapee, R.M. (2000). The origins of social phobia. Behavior Modification, 24, 102-129.

Hymel, S., Rubin, K.H., Rowden, L. \& LeMare, L. (1990). Children's peer relationships: longitudinal prediction of internalizing and externalizing problems from middle to late adolescence. Child Development, 61, 2004-2021. 
Juster, H.R., Heimberg, R.G., \& Holt, C.S. (1996). Social phobia: Diagnostic issues and review of cognitive behavioral treatment strategies. Progress in Behavior Modification, 20, 74-98.

Kendall, P.C., \& Chansky, T.E. (1991). Considering cognition in anxietydisordered children. Journal of Anxiety Disorders, 5, 167-185.

Kendall, P.C. \& Warman, M.J. (1996). Anxiety disorders in youth: diagnostic efficiency across DSM-III-R and DSM-IV. Journal of Anxiety Disorders, 10, 452463.

Kovacs, M. (1985). The Children's Depression Inventory (CDI). Psychopharmacology, 21, 995-998.

Lodge, J., Tripp, G., \& Harte, D.K. (2000). Think-aloud, thought-listing, and video-mediated recall procedures in the assessment of children's self-talk. $\underline{\text { Cognitive }}$ Therapy and Research, 24, 399-418.

Lucock, M.P., \& Salkovskis, P.M. (1988). Cognitive factors in social anxiety and its treatment. Behavior Research and Therapy, 26, 297-302.

Mannuzza, S., Fyer, A.J., Liebowitz, M.R., \& Klein, D.F. (1990). Delineating the boundaries of social phobia: Its relationship to panic disorder and agoraphobia. Journal of Anxiety Disorders, 4, 41-59.

Melfsen, S. \& Florin, I. (2002). Do socially-anxious children show deficits in classifying facial expressions of emotions? Journal of Nonverbal Behavior, 26, 109126. 
Muris, P., Merckelbach, H., \& Damsma, E. (2000). Threat perception bias in non-referred, socially anxious children. Journal of Clinical Child Psychology, 29, 348-359.

Ost, L.G. (1987). Age of onset in different phobias. Journal of Abnormal Psychology, 96, 223-229.

Ost, L.G. \& Hugdahl, K. (1981). Acquisition of phobias and anxiety response patterns in clinical patients. Behaviour Research and Therapy, 19, 439-447.

Pina, A.A., Alfano, C.A., Viana, A.G., Weems, C.F. \& Silverman, W.K. (March, 2004). Cognitive Errors as Moderators of Treatment Effects and Maintenance: A Comparison Cognitive Therapy and Education Support in the Treatment of Childhood Phobic and Anxiety Disorders. Poster presented at the annual meeting of the Anxiety Disorders Association of America, Miami, FL.

Pine, D. S., \& Grun, J. B. S. (1998). Anxiety disorders. In T. B. Walsh (Ed.), Child Psychopharmacology (1 ed., Vol. 17, pp. 115-144). Washington, DC: American Psychiatric Press Inc.

Rapee, R.M. \& Heimberg, R.G. (1997). A cognitive-behavioral model of anxiety in social phobia. Behaviour Research and Therapy, 35, 741-756.

Rapee, R.M. \& Lim, L. (1992). Discrepancy between self- and observerratings of performance in social phobics. Journal of Abnormal Psychology, 101, 728731.

Robins, L.N., Helzer, J.E., Weissman, M.M., Orvaschel, H., Greenberg, E., Burke, Jr., J.D., \& Regier, D.A. (1984). Lifetime prevalence of specific psychiatric disorders in three sites. Archives of General Psychiatry, 41, 949-958. 
Rubin, K.H., \& Mills, S.L. (1988). The many faces of social isolation in childhood. Journal of Consulting \& Clinical Psychology, 56, 916-924.

Schneier, F.R., Johnson, J., Hornig, C.D., Liebowitz, M.R., \& Weissman, M.M. (1992). Social phobia: Comorbidity and morbidity in an epidemiologic sample. Archives of General Psychiatry, 49, 282-288.

Schwarz, R.M., \& Garamoni, G.L. (1986). Cognitive assessment: a multibehavior, multimethod, multiperspective approach. Journal of Psychopathology and Behavioral Assessment, 8, 185-197.

Silverman, W.K., Kurtines, W.M., Ginsburg, G.S., Weems, C.F., Rabian, B., \& Serafini, L.T. (1999). Contingency management, self-control, and education support in the treatment of childhood phobic disorders: a randomized clinical trial. Journal of Consulting and Clinical Psychology, 67, 675-687.

Silverman, W.K., \& Albano, A.M. (1996). Anxiety Disorders Interview

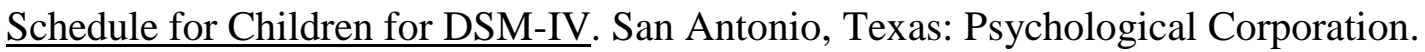
Silverman, W.K., Saavedra, L.M. \& Pina, A.A. (2001). Test-retest reliability of anxious symptoms and diagnoses with an anxiety disorders interview schedule for DSM-IV: child and parent versions. Journal of the American Academy of Child and Adolescent Psychiatry, 40, 937-944.

Solyom, L., Ledwidge, B., \& Solyom, C. (1986). Delineating social phobia. British Journal of Psychiatry, 149, 464-470. 
Spence, S.H., Donovan, C. \& Brechman-Toussaint, M. (2000). The treatment of childhood social phobia: The effectiveness of a social skills training-based, cognitive-behavioral intervention, with and without parental involvement. Journal of Child Psychology and Psychiatry, 41, 713-726.

Spence, S.H., Donovan, C., \& Brechman-Toussaint, M. (1999). Social skills, social outcomes, and cognitive features of childhood social phobia. Journal of Abnormal Psychology, 108, 211-221.

Spurr, J.M. \& Stopa, L. (2002). Self-focused attention in social phobia and social anxiety. Clinical Psychology review, 22, 947-975.

Stemberger, R.T., Turner, S.M., Beidel, D.C. \& Calhoun, K.S. (1995). Social phobia: an analysis of possible developmental factors. Journal of Abnormal Psychology, 104, 526-531.

Stopa, L. \& Clark, D.M. (1993). Cognitive processes in social phobia. Behaviour Research and Therapy, 31, 255-267.

Tracey, S.A., Chorpita, B.F., Douban, J. \& Barlow, D.H. (1997). Empirical evaluation of DSM-IV generalized anxiety disorder criteria in children and adolescents. Journal of Clinical Child Psychology, 26, 404-414.

Turner, S.M., Beidel, D.C., Cooley, M.R., Woody, S.R., \& Messer, S.C. (1994). A multicomponent behavioral treatment for social phobia: Social Effectiveness Therapy. Behaviour Research \& Therapy, 32, 381-390.

Turner, S.M., Beidel, D.C. \& Townsley, R.M. (1990). Social phobia: relationship to shyness. Behaviour Research and Therapy, 28, 497-505. 
Turner, S.M., Beidel, D.C., Dancu, C.V. \& Keys, D.J. (1986).

Psychopathology of social phobia and comparison to avoidant personality disorder. Journal of Abnormal Psychology, 95, 389-394.

Velosa, J. F. \& Riddle, M. A. (2000). Pharmacologic treatment of anxiety disorders in children and adolescents. Psychopharmacology, 9, 119-133.

Westenberg, P.M., Drewes, M.J., Goedhart, A.W., Siebelink, B.M., Treffers, P.D.A. (2004). A developmental analysis of self-reported fears in late childhood through mid-adolescence: Social-evaluative fears on the rise? Journal of Child Psychology \& Psychiatry, 45, 481-495.

Wilens, T. E., Spencer, T. J., Frazier, J., \& Biederman, J. (1998). Child and adolescent psychopharmacology. In Ollendick \& Hersen (Eds.), Handbook of Child Psychopathology (pp. 603-636). New York: Plenum Press.

Wittchen, H.U., Stein, M.B. \& Kessler, R.C. (1999). Social fears and social phobia in a community sample of adolescents and young adults: prevalence, risk factors, and comorbidity. Psychological Medicine, 29, 309-323. 
